1992

\title{
Understanding Disagreement, the Root Issue of Jurisprudence: Applying Wittgenstein to Positivism, Critical Theory, and Judging
}

Thomas Morawetz

University of Connecticut School of Law

Follow this and additional works at: https://opencommons.uconn.edu/law_papers

Part of the Judges Commons, Jurisprudence Commons, Law and Philosophy Commons, and the Legal Theory Commons

\section{Recommended Citation}

Morawetz, Thomas, "Understanding Disagreement, the Root Issue of Jurisprudence: Applying Wittgenstein to Positivism, Critical Theory, and Judging" (1992). Faculty Articles and Papers. 45.

https://opencommons.uconn.edu/law_papers/45 


\section{HEINONLINE}

Citation: 141 U. Pa. L. Rev. 371 1992-1993

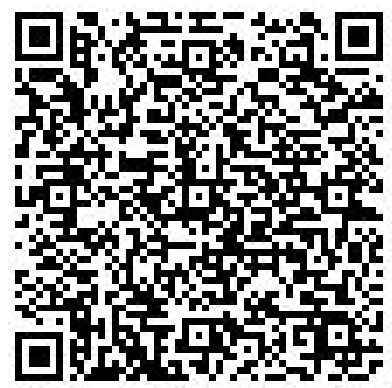

Content downloaded/printed from

HeinOnline (http://heinonline.org)

Mon Aug 15 17:11:27 2016

-- Your use of this HeinOnline PDF indicates your acceptance of HeinOnline's Terms and Conditions of the license agreement available at http://heinonline.org/HOL/License

-- The search text of this PDF is generated from uncorrected OCR text.

-- To obtain permission to use this article beyond the scope of your HeinOnline license, please use:

https://www.copyright.com/ccc/basicSearch.do?

\&operation $=$ go\&search Type $=0$

\&lastSearch $=$ simple\&all $=$ on\&titleOrStdNo $=0041-9907$ 


\section{University of Pennsylvania \\ Law Review}

FOUNDED 1852

Formerly

American Law Register

\section{ARTICLES}

UNDERSTANDING DISAGREEMENT, THE ROOT ISSUE OF JURISPRUDENCE: APPLYING WITTGENSTEIN TO POSITIVISM, CRITICAL THEORY, AND JUDGING

\section{THOMAS MORAWETZ†}

My judgments themselves characterize the way I judge, characterize the nature of judgment. ${ }^{1}$

† Professor of Law, University of Connecticut School of Law. I am very grateful to Scott Altman, Ruth Gavison, Mark Miller, Stephen Munzer, Jeremy Paul, Samuel Pillsbury, Margaret Jane Radin, and Michael Shapiro for many insights and valuable suggestions. I owe special thanks to my research assistant, Melinda Westbrook, for the care and intelligence she brought to this project.

${ }^{1}$ LUDWIG WITTGENSTEIN, ON CERTAINTY 22 (G.E.M. Anscombe \& G.H. von Wright eds., Denis Paul \& G.E.M. Anscombe trans., 1969). 


\section{TABLE OF CONTENTS}

I. ANTIFOUNDATIONALISM AND CONTEMPORARY

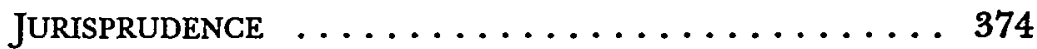

A. Where We Are .................. 374

B. Where We Need to Go ............... 378

II. LaW as a Deliberative Practice . . . . . . . . . 383

A. Rules, Games, and Judgments ............ 384

1. The Hardest Question: A Tale of Two

Metaphors ................... 384

a. Centripetal and Centrifugal Reasoning ...... 385

b. The Metaphor of Games ............. 386

c. Applying the Game Metaphor to Law . . . . . . . . 387

2. Judicial Interpretation . . . . . . . . 389

a. Consensus Theory ............... . 390

b. Antifoundationalism .............. 390

c. Implications for Theory and Practice ....... 393

3. Critique ..................... 394

B. Practices and Deliberative Practices . . . . . . . . . 396

1. Practices in General . . . . . . . . . . . . 396

2. Linguistic Practices . . . . . . . . . . 397

3. Deliberative Practices . . . . . . . . . . . . 398

a. Understanding Disagreement . . . . . . . 398

b. Agreement and the Bounds of Practice ... . . . 399

c. Discourse and Debate .............. 401

d. Persuasion ..................... 402

C. Judicial Decision as a Deliberative Practice ....... 403

1. Disagreement Among Judges .......... 405

2. The Bounds of Judicial Disagreement ....... 405

3. The Driving Force of Judicial Persuasion ..... 406

4. The Grounds of Persuasion and Change ... . . . 409

D. Immersion in Practice as an Obstacle to Theory . . . . . . 409

III. LEgal Positivism AND LAW AS a Deliberative

PRACTICE . . . . . . . . . . . . . . . . . . . 412

A. Positivism and Judging . . . . . . . . . . . . 412

1. Positivism and the Identification of Law ...... 412

2. Raz's Positivism ................ 413

3. Dworkin's Criticisms .............. 414 
B. The Limitations of Positivism . . . . . . . . . 414

1. Criteria of Validity . . . . . . . . . . . 415

2. The Meaning of Legal Justification ........ 416

3. Participants and Theorists ............ 418

4. Dissolving the Dichotomies of Positivism . . . . . 420

a. Existing Law and New Law . . . . . . . . . . . 420

b. Law and Gaps ... . . . . . . . . . . . . . 422

c. Law as It Is and Law as It Ought to Be . . . . . . 423

C. Dworkin's Criticisms and Deliberative Practices ...... 423

1. The Self-Understanding of Judges . . . . . . . 424

a. The Bases of Disagreement . . . . . . . . . 425

b. Understanding Other Judges . . . . . . . . 425

c. The "Best" Interpretation of the Law . . . . . . . 426

2. The Completeness of Law . . . . . . . . . 427

IV. ANTIFOUNDATIONALISM AND PRAGMATISM $\ldots \ldots \ldots \ldots 428$

A. From Old to New Jurisprudence . . . . . . . . . . 429

B. The Limits of Critical Theory . . . . . . . . . . 430

1. Myths of Value Pluralism ............ 430

2. Conceptual Frameworks .............. 434

a. Forms of Conceptual Relativity ........... 435

b. Intractable Questions . . . . . . . . . . 436

c. Abandoning Conceptual Relativity ......... 438

3. Semantic Relativity . . . . . . . . . . . . . 439

C. Applying the Lessons: Pragmatism as Legal Theory ... 441

1. Rorty's Pragmatism ... . . . . . . . . . 443

a. Rorty on Solidarity and Individuality ........ 444

b. Rorty on Theory and Practice ............ 446

c. Rorty's Influence . . . . . . . . . . . . 447

2. Fish and Interpretive Communities . . . . . . . 449

a. Fish and Deliberative Practices .......... 450

b. Fish as Pure Theorist .............. 451

c. Fish on Interpretive Communities . . . . . . . 452

3. Acceptable Pragmatism and Banal Pragmatism .. 452 CoNCLUSION . . . . . . . . . . . . . . . . . 455 


\section{ANTIFOUNDATIONALISM AND CONTEMPORARY JURISPRUDENCE}

\section{A. Where We Are}

A pervasive theme of recent legal theory is profound skepticism about the possibility of consensus in social values and goals. ${ }^{2}$ Accompanying such skepticism is multifaceted doubt about objectivity, rationality, and the possibility of social progress. ${ }^{3}$ Skeptical theorists reject the idea of shared intellectual foundations and therefore are generally called antifoundationalists. ${ }^{4}$

2 This theme, and the various social and legal arguments that elaborate it, are at the heart of critical theory-which embraces critical legal theory, critical feminism, and critical race studies. Mark Kelman, for example, says that from the standpoint of critical legal studies, mainstream (liberal) legal thought is in fact beset "not by 'competing concerns' artfully balanced until a wise equilibrium is reached, but by irreducible, irremediable, irresolvable conflict." MARK KELMAN, A GUIDE TO CRITICAL LEGAL STUDIES 3 (1987). Martha Minow cites the philosophers A.J. Ayer and W.V. Quine for the proposition that "although we can alter the theory we use to frame our perceptions of the world, we cannot see the world unclouded by preconceptions. The impact of the observer's perspective may be crudely oppressive. Yet, we continue to believe in neutrality." Martha Minow, Foreword: Justice Engendered, 101 HARV. L. REv. 10, 46 (1987). See also Mari J. Matsuda, Looking to the Bottom: Critical Legal Studies and Reparations 22 HARV. C.R.-C.L. L. REv. 323 (1987) (commenting on the irreducible distinctiveness of racial points of view); Robin L. West, The Difference in Women's Hedonic Lives: A Phenomenological Critique of Feminist Legal Theory, 3 WIS. WOMEN's L.J. 81 (1987) (discussing the irreducible experiential differences between men and women and the perceptions that follow from them).

${ }^{3}$ Although critical writers generally attack objectivity claims, they frequently take different positions on the notion of social progress. Catharine MacKinnon echoes many other writers when she says that the notion of objectivity is used to mask "such power over reality as comes from methodological hegemony over the means of knowing." Catharine A. Mackinnon, TOWARD a FEMINIST THEORY OF THE STATE 107 (1989). On the question of social progress, compare Robert Gordon's observation that the core of traditional liberal thought is the idea that " $[t]$ here is an objective, determined, progressive social evolutionary path" with the confidence of many feminist and critical race theorists that their work brings us closer to a genuine understanding and implementation of equality. Robert W. Gordon, Critical Legal Histories, 36 STAN. L. REV. 57, 61 (1984).

4 Debates between legal foundationalists and antifoundationalists reflect pervasive movements in philosophy. Richard Rorty describes and promotes an antifoundationalist approach to traditional philosophical issues. He describes antifoundationalism as the view that

the notion of knowledge as accurate representation, made possible by special mental processes, and intelligible through a general theory of representation, needs to be abandoned.

[T] he attempt (which has defined traditional philosophy) to explicate 'rationality' and 'objectivity' in terms of conditions of accurate representation is a self-deceptive effort to eternalize the normal discourse of the day... 
Antifoundationalist arguments have so thoroughly taken hold of the legal imagination that contemporary legal theory seems discontinuous with its quite recent past. This discontinuity has two aspects. First, the new jurisprudence sees the old jurisprudence as naive and superficial, especially in its treatment of value consensus. ${ }^{5}$ The aim of the new theorists is not to answer and refute positivism and liberalism, but to subvert them. ${ }^{6}$ Second, the new jurisprudence is only tangentially about law and legal reasoning; instead, it is primarily about language, thought, and will, about meaning and truth. Legal implications are treated almost as incidental. ${ }^{7}$

The transition from the old to the new jurisprudence, best exemplified by critical theory, involves three kinds of destabilizing arguments-arguments that in turn defend moral, conceptual, and semantic relativity. ${ }^{8}$ The moral argument destabilizes liberalism

RICHARD RORTY, PHILOSOPHY AND THE MIRROR OF NATURE 6, 11 (1979).

${ }^{5}$ Many writers go further and characterize liberal assumptions about value consensus as devious and repressive. The dominant groups in society, on this view, universalize their interests and experience and repress the self-expression of groups (e.g. women and minorities) without power. According to Robert Gordon, one can represent law as a legitimating ideology in the view that "[t]he ruling class induces consent and demobilizes opposition by masking its role in widely shared utopian norms and fair procedures, which it then distorts to its own purposes." Gordon, supra note 3, at 93 . Gordon himself seems to proffer an account wherein these preferences are concealed even from the actors themselves because ${ }^{\text {" }}[t]$ he discourse of law-its categories, arguments, reasoning modes, rhetorical tropes, and procedural rituals-fits into a complex of discursive practices that together structure how people perceive." $I d$. at 95 .

${ }^{6}$ In the introduction to Postmodern Jurispredence, Douzinas and Warrington observe that

[t]he orthodox jurisprudence of modernity constructs theories that portray the law as a coherent body of rules and principles. ... Its predominant strategy is to try and weave the legal texts into a single, seamless veil .... In this, postmodern theory could not be more different. It distrusts all attempts to create large-scale, totalising theories in order to explain social phenomena. . . . It tells small-scale, provisional, open stories about our lives and the world. . . . [Therefore,] the bodies of theory brought together here are not staging a confrontation."

COSTAS DOUZINAS ET AL., POSTMODERN JURISPRUDENCE ix-x (1991).

${ }^{7}$ I am not necessarily offering this point as criticism. My examination of antifoundationalist theories in Part IV of this article is itself a discussion of thought and will, meaning and truth-applicable generally to deliberative acts of many kinds.

${ }^{8}$ These are not three distinct and separate arguments. Arguments for conceptual relativity tend to generalize arguments for moral relativity. They put forward a general epistemological position which relativizes both facts and values and which (perhaps) questions or erodes the distinction between facts and values. Arguments for semantic relativity focus not so much on thought and understanding as on 
and faith in public values with an assault on the objectivity of rights, encapsulated in the claim that all law is politics. ${ }^{9}$ The conceptual argument impeaches ideological neutrality by uncovering multiple narratives and alternative voices that coexist in time and space and offer irreconcilable ways of ordering experience. ${ }^{10}$ Finally, the semantic argument undercuts communication with deconstructive arguments that characterize meaning as hearer-determined. ${ }^{11}$

The pedigree of antifoundationalism is endlessly disputable. Any era, suitably interpreted, will yield antecedents. ${ }^{12}$ What is distinctive about contemporary theorists is that they address the

communication, and they raise questions about constancy of meaning across speaker/ hearer, writer/reader dyads.

${ }^{9}$ Mark Tushnet, for example, says that

interpretivism and neutral principles attempt to complete the world view of liberalism by explaining how individuals may form a society. $[\mathrm{H}]$ owever, ... the only coherent basis for the requisite continuities of history and meaning is found in the communitarian assumptions of conservative social thought.... If I am correct, the liberal account of the social world is inevitably incomplete, for it proves unable to provide a constitutional theory of the sort that it demands.

Mark V. Tushnet, Following the Rules Laid Down: A Critique of Interpretivism and Neutral Principles, 96 HARV. L. REV. 781, 785 (1983). Roberto Unger explains how the liberal account seeks to use the concept of rights:

The rights and principles school . . . claims to discern in the leading ideas of the different branches of law, especially when illuminated by a scrupulous, benevolent, and well-prepared professional elite, the signs of an underlying moral order that can then serve as the basis for a system of more or less natural rights.

Roberto M. Unger, The Critical Legal Studies Movement 13 (1986). Duncan Kennedy strikes similar notes when he says, "I will use the term liberalism to describe the mode of mediation or denial that gradually killed off its rivals, before it finally succumbed to the problems it was designed to solve." Duncan Kennedy, The Structure of Blackstone's Commentaries, 28 BUFF. L. REV. 209, 216 (1979).

${ }^{10}$ Arguments defending conceptual relativity are frequently defended by feminist theorists and race theorists. For example, in discussing what she calls the "separation thesis," Robin West concludes that legal theory for men is essentially different in its fundamental assumptions than it is for women. Robin West, Jurisprudence and Gender, 55 U. CHI. L. REv. 1, 2-3 (1988). Mari Matsuda argues that race affords a theorist a particular conceptual scheme and that racial perspective "cuts across class lines. . . . There is something about color that doesn't wash off as easily as class." Matsuda, supra note 2, at 360-61.

${ }^{11}$ Sanford Levinson comments that in light of "ambiguities of interpretation, many legal theorists have substituted for the hermeneutics of objective interpretation what Gerald Graff has termed a 'hermeneutics of power,' where one emphasizes the political and social determinants of reading texts one way as opposed to another." INTERPRETING LAW AND LITERATURE xiii (Sanford Levinson \& Steven Mailloux eds., 1988) (quoting Gerald Graff, Textual Leftism, 49 PARTISAN REV. 566 (1982)).

12 Plausible examples include some of the pre-Socratic philosophers, the Sophists, Nicholas of Cusa, Kierkegaard, and Nietzsche. 
erosion of foundations on all three fronts: moral, conceptual, and semantic. At least one way of characterizing the elusive and pervasive notion of postmodernism is by reference to these arguments and the attitudes they express. ${ }^{13}$

Some theorists summarize the destabilizing arguments to conclude that any pooling of goals and ideals must be the adventitious result of a "conversation" among persons with irreconcilable ways of thinking. ${ }^{14}$ At one level removed from substantive theory (at the level of "How shall we understand what we do?" rather than the level of "What shall we do?"), the emergent theory of truth and meaning is a version of pragmatism. ${ }^{15}$ Pragmatists argue that what is true and has meaning achieves that status provisionally; justificatory arguments for one position or another run out. ${ }^{16}$

\section{B. Where We Need to Go}

The high priests of antifoundationalism draw inspiration from the work of the philosopher Ludwig Wittgenstein, ${ }^{17}$ much of it

13 See, e.g., DouziNAS, supra note 6, at 3-51 (arguing that modernist discourses of law contain the unsettling thematics of postmodernity which these texts attempt to deny); Postmodernism and Law: A Symposium, 62 U. CoLO. L. REV. 439-598 (1991).

${ }^{14}$ According to Rorty:

[t]o look for commensuration rather than simply continued conversation-to look for a way of making further redescription unnecessary by finding a way of reducing all possible descriptions to one-is to attempt escape from humanity. To abandon the notion that philosophy must show all possible discourse naturally converging to a consensus ... would be to abandon the hope of being anything more than merely human.

RORTY, supra note 4, at 376-77.

15 For Rorty's definition of pragmatism, see infra text accompanying notes 207-09. See also Symposium, Renaissance of Pragmatism in American Legal Thought, 63 S. CAL. L. REV. 1569-1819 (1990) (spelling out the implications of pragmatism for legal theory).

16 I shall examine how these theoretical moves define a skeptical posture of doubt about the objectivity of shared values, doubt about one's own impartiality, and doubt about both discovering the meaning of texts and imparting meaning to texts. The attitude appropriate to such doubts is modesty about one's goals, understanding, and powers. Doubts and modesty, on this analysis, are equally appropriate for actors (judges, attorneys) and theorists. The forms of destabilization affect practical and theoretical aims equally. And yet this is not the whole story. In both cases, as feminists and other critical theorists are quick to make clear, cutting loose from shared values, impartial rules, and fixed meanings also empowers those who do not share the prevailing values or benefit from the prevailing rules.

${ }^{17}$ For the best recent discussion of Wittgenstein's views on philosophy, see generally ROBERT J. ACKERMAN, WITTGENSTEIN's CITY (1988). Surprisingly few writers, however, have addressed Wittgenstein's import for legal theory directly. But see Stephen Brainerd, The Groundless Assault: A Wittgensteinian Look at Language, 
filtered through the influential writings of Richard Rorty ${ }^{18}$ and Stanley Fish. ${ }^{19}$ Rorty explicitly and Fish implicitly play upon Wittgenstein's remarks about the limits of justification and the constructive character of language. ${ }^{20}$ In two respects, however, the recent appropriation of Wittgenstein's ideas for legal theory has been deficient.

First, critical theorists have given little attention to the relationship between practice and theory. The relationship, on first impression, seems well captured by the distinction between being inside and being outside a way of thinking and being. ${ }^{21}$ Accordingly, the practitioner takes a way of proceeding for granted, and the theorist attends self-consciously and critically to the practition-

Structuralism, and Critical Legal Theory, 34 AM. U. L. REV. 1231 (1985) (outlining some of the intellectual moves that have shaped both critical legal theory in general and structuralism in particular); Scott Landers, Wittgenstein, Realism, and CLS: Undermining Rule Skepticism, 9 LAW \& PHIL. 177 (1990); Symposium, Legal Theory and Wittgensteinian Thought, 3 CANADIAN J.L. \& JURIS. 3 (1990).

${ }^{18}$ See supra notes 4 \& 14.

${ }^{19}$ Stanley Fish's most important essays are collected in two volumes. See STANLEY FISH, DOING WHAT COMES NATURALly (1989) [hereinafter FISH, NATURALLY]; STANLEY FISH, Is THERE A TEXT IN THIS CLASS? (1980) [hereinafter FISH, TEXT]. His essays on the connections between literary theory and legal theory appear in the former volume.

${ }^{20}$ Wittgenstein makes the following comments on this subject:

189. At some point one has to pass from explanation to mere description. $\cdots$...

191. Well, if everything speaks for an hypothesis and nothing against it-is it then certainly true? One may designate it as such.-But does it certainly agree with reality, with the facts?-With this question you are already going round in a circle.

192. To be sure there is justification; but justification comes to an end. WITTGENSTEIN, supra note 1 , at 26-27.

${ }^{21}$ In The Concept of Law, H.L.A. Hart uses the notion of the "internal aspect" of rules to distinguish rules from habits:

By contrast [with a habit], if a social rule is to exist some at least must look upon the behaviour in question as a general standard to be followed by the group as a whole. A social rule has an 'internal' aspect, in addition to the external aspect which it shares with a social habit and which consists in the regular uniform behaviour which an observer could record.

H.L.A. HART, THE CONCEPT OF LAW 55 (1961). See also NeIL MACCORMICK, LEGAL REASONING AND LEGAL. THEORY 275-92 (1978). My distinction between being inside or outside a practice differs from Hart's in two respects. First, a theorist who is outside the practice in my sense has an "internal" point of view in Hart's sense insofar as she deploys the notion of rules as constraints and guides for action. Second, my sense of being inside a practice goes further than Hart's "internal aspect." I refer to individuals within the practice as having a commitment to a particular interpretive strategy for applying rules and norms in the light of a conception of the purposes they serve. 
er's way of proceeding. But Wittgenstein himself had well-founded misgivings about the very possibility of theory. He stressed that all persons-theorists and practitioners alike-inhabit ways of proceeding (thinking, acting, taking things for granted) and cannot step outside. ${ }^{22}$ The possibility of doing anything, including the possibility of propounding theories, depends on inhabiting a way of speaking and thinking. ${ }^{23}$ If this is true, then the relationship between theory and practice may not be an inside/outside relationship but a relationship of two different ways of being inside. To take this position is the beginning, not the end, of wisdom about theory and practice and about its acute implications for legal theory. ${ }^{24}$

The second area of concern is that antifoundationalists fail to appreciate fully the heterogeneous and complex nature of our belief systems. They assume that a single description or phrase (for instance, "value-bound" or "conceptually relative") describes all of one's beliefs collectively. But when we inhabit a way of proceeding (of thinking, acting, taking things for granted), we have different postures toward different beliefs. Our beliefs vary among several dimensions. One is whether they are controversial. Some beliefs, including many based on religious, political, or moral convictions, are inherently controversial and widely disputed; other beliefs, for example beliefs about historical facts, linguistic definitions, physics and biology, are often widely shared and little discussed or controverted. ${ }^{25}$

${ }^{22}$ According to Wittgenstein:

127. The work of the philosopher consists in assembling reminders for a particular purpose.

128. If one tried to advance theses in philosophy, it would never be possible to question them, because everyone would agree to them.

LudWic WittGenstein, PhILOSOPhiGal InVestiGations 50 (G.E.M. Anscombe trans., 1953).

220. The reasonable man does not have certain doubts.

221. Can I be in doubt at will?

222. I cannot possibly doubt that I was never in the stratosphere. Does that make me know it? Does it make it true?

WITTGENSTEIN, supra note 1, at 29.

${ }^{23}$ The position is defended at length by Fish. See supra note 19; $c$. JEAN-FrançOIs LyotaRd \& JEAN-LouP THÉBAUD, JUST GAMING 43 (Wlad Godzich trans., 1985) (" $[T]$ here is no outside; there is no place from which one could photograph the whole thing.").

${ }^{24}$ See infra text accompanying notes 62-66.

${ }^{25}$ This is obviously an oversimplification. It is more nearly correct to say that within each area-religion, biology, morality, etc.-some matters are settled (for the time being) and others are controversial. Nevertheless, the matters that arouse 
A second dimension is centrality to the individual. Some of my beliefs, whether controversial or not, are closely held. I adhere to them, it seems, at the price of my own identity and sanity and use them as tests and justifications for other beliefs. Some of my beliefs, on the other hand, are easily dislodged by counterargument or counterexperience. ${ }^{26}$

Cutting across these two distinctions among beliefs is a structural distinction among the indescribably varied ways in which we use beliefs or facts ${ }^{27}$ of one kind to support or justify beliefs of other kinds. Contemporary theorists pay too little attention to the important fact that persons have idiosyncratic and individual ways of sorting knowledge and of reasoning. There is no given ordering among our beliefs such that some are logically basic or foundational.

For example, we all have beliefs about psychology, history, economics, physics; about what is good and bad, possible and impossible, desirable and undesirable, and so on. One person may support normative conclusions with historical, psychological, sociological, economic, or moral arguments, or several kinds of

controversy in everyday life characteristically involve moral and political disagreement, while claims about history and science are controversial among those who are specialists and have a vested interest in a research program.

${ }^{26}$ In On Certainty, Wittgenstein repeatedly draws this contrast between propositions that are in practice empirically tested and those that are fundamental to one's way of proceeding. Consider the following passages:

55. So is the hypothesis possible, that all the things around us don't exist? Would that not be like the hypothesis of our having miscalculated in all our calculations?

446. But why am I so certain that this is my hand? Doesn't the whole language-game rest on this kind of certainty?

...

617. Certain events would put me into a position in which I could not go on with the old language-game any further. In which I was torn away from the sureness of the game.

Indeed, doesn't it seem obvious that the possibility of a language-game is conditioned by certain facts?

....

638. "I can't be making a mistake" is an ordinary sentence, which serves to give the certainty-value of a statement. And only in its everyday use is it justified.

WITTGENSTEIN, supra note 1 , at $9,58,82,84$.

${ }^{27}$ For my purposes it is indifferent whether one uses the term "facts" or "beliefs" to refer to those matters a person holds true and is prepared to justify. "Beliefs" is appropriate when one is calling attention to the intentional status of the proposition. 
arguments intimately combined. A person may use historical arguments to back economic conclusions (and vice versa), marshall psychological arguments in historical discourse, explain psychological facts with biological ones-or one can forego such reductive moves. ${ }^{28}$

Antifoundationalists generally offer a simple and stream-lined version of relativism. They disparage references to publicly shared values without considering the varied justificatory arguments available to support them. In particular, they dismiss justification by reference to what is publicly shared and universally accepted as masking justification by reference to what is preferred by the individual or the individual's group. ${ }^{29}$ In fact, both kinds of justification coexist in deliberative discourse-and a more insightful version of relativism would examine the way in which individuals use both kinds of justification and how they are constrained by what is intelligible and acceptable to fellow discussants. ${ }^{30}$

Similarly, antifoundationalist writers offer a simplistic relativism when they attack the neutrality of conceptual standpoints regardless of the concepts and arguments at issue. All claims, for them, are equally partial, disputable, and controvertible moves in a "conversation." 11 The machinery of antifoundationalism thus homogenizes reasoning in general and legal reasoning in particular, and that homogeneity is expressed in a pragmatic theory of truth. ${ }^{32}$

This characteristic of antifoundationalism is its Achilles' heel,

${ }^{28}$ The notion that no domain of knowledge has explanatory priority over others inherently and objectively has become commonplace in contemporary philosophy. The prevailing view is that explanatory patterns are determined by the interests of the inquirer. See, e.g., RICHARD J. BERNSTEIN, BEYOND OBJECTIVISM AND RELATIVISM (1985); JURGEN HABERMAS, KNOWLEDGE AND HUMAN INTERESTS 196-97 (Jeremy J. Shapiro trans., 1968); RATIONALITY AND RELATIVISM (Martin Hollis \& Stephen Lukes eds., 1982).

${ }^{29}$ A particularly exhaustive attempt to reduce all value justifications to masked preferences is the critique offered by John Hart Ely. See JOHN H. ELY, DEMOCRACY AND DISTRUST 43-72 (1980).

${ }^{30}$ This latter and very different kind of relativism is the thesis that I develop and defend in this article.

${ }^{31}$ In this way the framework set up by Rorty seems generally applicable. See supra note 14. These matters are discussed at length in Part IV, infra.

32 Another way of expressing this criticism is that simple relativism, which homogenizes all justificatory strategies and which is expressed by some forms of pragmatism, represents the point of view of the pure outsider to deliberative practices. It ignores the complexity of justificatory strategies that are incumbent on any practitioner within a deliberative practice, on someone for whom the distinctions between partiality and neutrality, personal preference and external norm, etc., remain coherent distinctions. These points are discussed in Part II, infra. 
the key to its limits and mistakes in general and as applied within legal theory. In this article, I analyze those mistakes and propose a more adequate account of the heterogeneity of reasoning and its implications. In my view, understanding agreement and disagreement in legal reasoning requires a careful examination of the relationship between the individual and the group. How are the reasoning strategies of individuals parasitic upon preexisting practices? In what sense are the strategies of individuals unique? How do the variant strategies of individuals produce disagreement as well as the possibility of addressing such disagreement with shared concepts? What allows individuals to transcend their own strategies by using theory to view their practice as a whole? In other words, I shall describe legal reasoning by looking at it as a "deliberative practice."

The main sections of this article examine legal reasoning to show the jurisprudential importance of the two problems I have raised: the inside/outside problem (the relation of practice and theory) and the heterogeneity of justification and belief. Part II explains the idea of a deliberative practice, implicitly relying on Wittgenstein's insights about reasoning, justification, and belief. Part III demonstrates how the understanding of law as a deliberative practice helps to resolve several key issues concerning the merits and defects of a positivist description of law. ${ }^{33}$ Part IV discusses the limitations of antifoundationalism and pragmatism by examining the consequences of their relative inattention to the same two problems, the inside/outside dilemma and the heterogeneity of justification. Characterizing law as a deliberative practice sets us on the road to three goals: (1) giving an elastic and convincing description of legal reasoning; (2) building bridges between the old jurisprudence and the new; and (3) examining the foundations of critical theory by questioning the way in which it claims to destabilize value, conceptual coherence, and meaning.

${ }^{33}$ One might reasonably object to calling debates over the nature of law and the merits of positivism "old" jurisprudence. Among American writers, discussions of positivism are frequently subsumed under discussions of formalism. See, e.g., THE RULE OF LAW: IDEAL OR IDEOLOGY (Allan C. Hutchinson \& Patrick Monahan eds., 1987); Frederick Schauer, Formalism, 97 YALE L.J. 509 (1988); Ernest J. Weinrib, Legal Formalism: On the Immanent Rationality of Law, 97 YALE L.J. 949 (1988). 


\section{LaW as a Deliberative Practice}

The ways in which judges disagree, in method as well as result, have much in common with other kinds of deliberation; indeed, it is not misleading to think of deliberation as a genus and judicial deliberation as its species. In judicial deliberation, or any kind of deliberation, the relationship of the individual to the group is problematic. In one sense, the individual follows the same rules of reasoning as other members of the group and is therefore intelligible to them. But, in another sense, she has distinct strategies of understanding and decision-making insofar as she has a unique history and unique capacities. ${ }^{34}$

Legal philosophy has tended to ignore or at least skirt the issue of the relationship of the individual to the group (for example, the relation of the judge to the court on which she sits). Philosophers frequently seem to make one of three simplistic assumptions. Some simply assume that all judges follow the same rules, at least to the point at which they exhaust such rules. ${ }^{35}$ Others assume that each judge has a personal way of reasoning, distinct and separate from other judges. ${ }^{36}$ Still others attribute to judges (and all persons)

34 The pervasive theme of Wittgenstein's reflections on philosophy, understanding, and language is arguably the notion that all understanding and language use depend on pre-existing practices within the community of language-users and fellowreasoners. Thus, Wittgenstein does not give as much attention to what individualizes one reasoner from another as I shall do in this article. My main point is that the individual does not create or initiate ex nihilo strategies of understanding and reasoning. Rather, she derives the ingredients from the pre-existing strategies of others and melds and modifies them in her own experience.

${ }^{35}$ This expresses the point of view of most positivists. Neil MacCormick summarizes H.L.A. Hart's position on decision-making as follows:

Hart does indeed affirm that law essentially comprises rules. He further affirms that a great part of legal business consists in the straightforward and uncontroversial application, observance and enforcement of rules. But he accepts, in partial agreement with the realists, that rules cannot settle everything. Being framed in language, rules are "open-textured" and often vague. ... So Hart concludes that within the framework of rules whose meaning is clear enough for some purposes, there is and must be a considerable range of discretion left open to judges and other officials.

NeIL MAcCoRMICK, H.L.A. HART 26 (1981) (emphasis omitted).

${ }^{36}$ Dworkin summarizes his best understanding of judicial decision-making when he says that

[1]aw as integrity ... requires a judge to test his interpretation of any part of the great network of political structures and decisions of his community by asking whether it could form part of a coherent theory justifying the network as a whole. 
certain distinctive ways of reasoning characteristic of persons of their gender, their social class, or their race. ${ }^{37}$ Viewing law as a deliberative practice allows us to relate the strategies of reasoning of judges, and individuals in general, to groups in a more interesting and illuminating way, one that compels us to rethink the nature of legal reasoning.

\section{A. Rules, Games, and Judgments}

\section{The Hardest Question: A Tale of Two Metaphors}

I begin by making clear the generality of the philosophical problem of explaining agreement and disagreement and using the idea of a deliberative practice to show that the hardest question, the central question, in philosophy is the coexistence of agreement and disagreement in all discourse.

This question is so familiar and general an expression of philosophical perplexity throughout its history that some may see it as banal. The possibility of philosophical analysis, or any kind of analysis or communication, is grounded on the commonality of what we think and what we say about experience and language. Whether the example of philosophical analysis is Plato on the good, Kant on understanding, or Rawls on justice, ${ }^{38}$ philosophical investigation is possible only if it refers to common experiences expressible in a common language. ${ }^{39}$

[The judge's] answer will depend on his convictions about the two constituent virtues of political morality we have considered: justice and fairness.

RONALD DWORKIN, LAW'S EMPIRE 245, 249 (1986).

${ }^{37}$ Critical legal theorists emphasize this kind of relativity among judges.

[Judges'] particular backgrounds, socialization, and experiences . . . result in a patterning, a consistency, in the ways they categorize, approach, and resolve social and political conflicts. This is a great source of the law's power: It reinforces, reflects, constitutes, and legitimizes dominant social and power relations without a need for or the appearance of control from outside.

David Kairys, Introduction, in THE POLITICS OF LAW 1, 5 (David Kairys ed., rev. ed. 1990).

${ }^{38}$ See Immanuel Kant, The Critique of Pure Reason (F. Max Müller trans., 1966); Plato, ThE REPUBlic (Raymond Larson trans. \& ed. 1979); JoHN RAWLS, A THEORY OF JUSTICE (1971).

${ }^{39}$ For a discussion of the central role of the self-conscious examination of language in the philosophy of the last fifty years, see THE LINGUISTIC TURN (Richard Rorty ed., 1967); IAN HackING, WhY Does Language MaTTER to PhILOSOPhY? (1975). 
At the same time, these matters-the nature of the good, or understanding, or justice-are never settled once and for all. Let's assume this is not because Plato or Rawls is a second-rate thinker but because deep-seated disagreement as well as agreement is characteristic of the understanding of experience. Persons, whether philosophers or not, are bound to disagree about the good or truth or justice as much as they agree. And the framework of agreement gives structure to the process of disagreeing. We argue about the good or justice and give reasons to persuade others to change their minds. Sometimes, perhaps often, persuasion fails and the arguments break down. Sometimes, perhaps often, the arguments barely get off the ground because the disagreements are profound. But sometimes they succeed. ${ }^{40}$ Although this all too familiar situation of agreeing and disagreeing is characteristic of all discourse, philosophy represents it in its most self-conscious form. It is so familiar that it defies easy analysis.

\section{a. Centripetal and Centrifugal Reasoning}

One useful metaphor for representing such agreement and disagreement is the distinction between centrifugal and centripetal forces. A centripetal force draws disparate elements to a common center or axis; a centrifugal force scatters elements by driving them away from a common center or axis. The pervasive emphasis of philosophical discourse has been centripetal. Recent philosophy seeks to clarify shared structures of experience and the shared language in which experience is expressed. It draws attention to a common center, clarifies the common conceptual scheme within which disparate experiences and interpretations of experience occur. To the extent that antifoundationalists question the possibility of a common center and assert that shared values, shared concepts, and a common language are illusory, their impact is centrifugal and therefore subversive. ${ }^{41}$

${ }^{10}$ Other things being equal, a theory that recognizes and explains the common experience of persuasion is superior to one that denies or ignores the experience.

11 To say that a theory is subversive is not necessarily criticism (nor is it necessarily praise). The aim of a theory, on my view, is to describe the centrifugalcentripetal mix of forces correctly-or, to speak nonmetaphorically, to describe the causes of and constraints on agreement and disagreement. 


\section{b. The Metaphor of Games}

The centripetal-centrifugal force metaphor is a process metaphor about moving toward or away from agreement. The second metaphor, the metaphor of games, is structural. It concerns the domain of tacit agreement that makes possible a realm of disagreeing discourse, of argument. The metaphor of games, or more specifically that of playing a game by rules, takes us closer to what is puzzling about agreement and disagreement.

Modern thinkers point out that common beliefs about experience and common practice in the use of language provide the context in which we form opinions, engage in discourse, interpret experience, agree and disagree. ${ }^{42}$ These common beliefs look like the rules of a game and our individual judgments/arguments seem comparable to the moves of players. Just as touchdowns and home runs are possible only because the shared rules of football and baseball are taken for granted, so too debates about esthetics or politics or morality appear possible only because we have a shared understanding of the range of mutually understandable positions and of the kinds of moves (of reasons) that count as possible justificatory moves in discourse. ${ }^{43}$ Moreover, just as with games, our shared participation in such discourse seems to rest on the fact that we have similar physical capacities, emotions, thought patterns, and linguistic capacities. ${ }^{44}$

The impulse to illuminate the acquisition of knowledge and making of judgments by appeal to the idea of games with rules is seductive. For example, Thomas Kuhn's influential attempt to distinguish normal science from scientific revolutions rests on the

42 This kind of observation leads philosophers like Wittgenstein and those influenced by him to speak about pervasive language-games. See WITTGENSTEIN, supra note 1 , at 2-15.

${ }^{43}$ Perhaps the most influential attempt to use the metaphor of games explicitly is in the early articles of John Rawls. See, e.g., John Rawls, Two Concepts of Rules, 64 PHIL. REV. 3 (1955). For Hart's use of the game metaphor, see HART, supra note 21, at $138-44$.

44 Wittgenstein makes a similar point, focusing not on similarities in physical and psychological endowment but rather on the beliefs that must be shared and taken for granted for linguistic transactions-indeed, for any investigating or questioning or judging-to occur:

343. But it isn't that the situation is like this: We just can't investigate everything, and for that reason we are forced to rest content with assumption. If I want the door to turn, the hinges must stay put.

344. My life consists in my being content to accept many things.

WITTGENSTEIN, supra note 1 , at 44 . 
claim that normal scientific research is pursued by investigators who agree on research procedures, standards of proof, and basic assumptions about what is to be investigated. ${ }^{45}$ They are able to carry on moves within the practice of scientific research because they play by the same rules. By contrast, a scientific revolution occurs when the rules themselves need to be changed.

The metaphorical use of the concept of a game quickly gives rise to difficulty. Is there a clear way to distinguish moves from rules? In true games, one has little trouble telling the rules from the individual moves and strategies of players. The rules of chess or baseball are uncontroversial and uncontroverted by players; they are constitutive ${ }^{46}$ and define what counts as scoring, as winning and losing, and as a move. The rules are what one must learn to become a participant. On the other hand, in discourse, in discussions of justice for example, the relation between what is assumed and what is controverted and arguable is itself unstable. In fact, the voluminous philosophical literature on justice shows fundamental disagreement about what the constitutive rules are for the "game" of making judgments about justice.

\section{c. Applying the Game Metaphor to Law}

How can one distinguish the rules for discussing the nature of justice from moves within the game? The fact that debates among judges are intelligible to the participants and all who read opinions implies that in some sense the participants are engaged in a shared practice and therefore are playing by the same rules. But what are the rules for deciding hard cases of law as opposed to moves made by judges in legal argument? Attempting to identify the rules of the

${ }^{45}$ See Thomas S. Kuhn, The Structure of Scientific Revolutions (2 International Encyclopedia of Unified Science, 2d ed. 1970).

${ }^{46}$ Rawls defines constitutive rules as follows:

$[\mathrm{T}]$ he rules of practices are logically prior to particular cases. This is so because there cannot be a particular case of an action falling under a rule of a practice unless there is the practice....

One may illustrate this point from the game of baseball. Many of the actions one performs in a game of baseball one can do by oneself or with others whether there is the game or not. For example, one can throw a ball, run, or swing a peculiarly shaped piece of wood. But one cannot steal a base, or strike out, or draw a walk, or make an error, or balk. . . . Striking out, stealing a base, balking, etc., are all actions which can only happen in a game .... The practice is logically prior to particular cases: unless there is the practice the terms referring to actions specified by it lack a sense.

Rawls, supra note 43 , at 25 . 
shared practice is Sisyphean. Such writers as Rawls and Dworkin distinguish formally between concepts and conceptions, implying that those who agree about concepts are playing by the same rules and that disagreements about conceptions are moves within the practice. ${ }^{47}$

This attempt to sort out moves from rules produces four distinct kinds of theoretical responses, based respectively on liberal consensus theory and on the moral, conceptual, and semantic arguments of antifoundationalists. Liberal theorists such as Ronald Dworkin and Owen Fiss try to justify a deep consensus about justice. ${ }^{48}$ They seek to settle disagreement by showing that the shared rules of the game, properly understood, yield clear answers to most legal controversies. Antifoundational theorists, by contrast, subvert such efforts by showing that disagreement is well grounded in irreconcilable and partial ways of understanding and describing experience.

This distinction between consensus and antifoundational theorists allows us to bring the two metaphors together. The consensus theorist offers a complex account of the rules of the game in an attempt to show that disagreement is largely a matter of misunderstanding the rules and that there is a conceptual and moral core to our practices that need only be elucidated. Consensus theorists thus exemplify the centripetal process of theorizing. By contrast, antifoundational theorists seek to offer an account that undercuts the possibility of resolving disagreement by shared conceptual and moral understandings. The impulses of the antifoundationalists are centrifugal. ${ }^{49}$ This is well illustrated by

47 "[I]t seems natural to think of the concept of justice as distinct from the various conceptions of justice and as being specified by the role which these different sets of principles, these different conceptions, have in common." RAWLS, supra note 38, at 5.

"I might say that I meant the family to be guided by the concept of fairness, not by any specific conception of fairness I might have had in mind. This is a crucial distinction which it is worth pausing to explore." RONALD DWORKIN, TAKING RIGHTS SERIOUSLY 134 (1977).

${ }^{48}$ See id.; DwORKIN, supra note 36; Owen M. Fiss, Objectivity and Interpretation, 34 STAN. L. REV. 739 (1982). Both writers exemplify what I have called the centripetal force of consensus theory.

${ }^{49} \mathrm{It}$ is important to note a sense in which the contrast between centrifugal and centripetal tendencies in theorizing oversimplifies the range of views on constitutional interpretation. Both Dworkin and critical theorists such as Duncan Kennedy emphasize the individuality of judging. Neither liberals nor their critics deny that judges reason in ways that reflect personal style, personal history, etc. All, in this sense, have learned some of the lessons of legal realism. But for liberals, the judge 
their approaches to constitutional interpretation.

\section{Judicial Interpretation}

The questions of how and why our efforts at understanding human experience yield agreement and disagreement are especially acute in law. Law involves the deliberate manipulation of some of the most important circumstances of life. Critical theory is surely correct in its claim that law is not just a product of our decisions but is constitutive of consciousness.

Why has judicial decision-making long been the main focus of jurisprudential discussion on the limits and processes of law? ${ }^{50}$ First, the received wisdom holds that judges are constrained by law in deciding cases, constrained by legal rather than political, moral, or prudential concerns. The limits of law are, so the theory goes, the limits of what is relevant in decision-making. Second, the traditional account says that hard cases are those in which judges run up against the limits of law, either because the law doesn't speak to these issues or because it speaks in ways that conflict sharply with other reasons for decision. The process of deciding such cases makes evident the relationship of legal and other justifications. Finally, because the Constitution trumps other law and presents the most intractable problems of interpretation, constitutional interpretation fills the spotlight. It does so whether theorists aim to carry out or to debunk this familiar jurisprudential agenda.

Approaches to constitutional interpretation illustrate well the conflict between centripetal and centrifugal theorizing. Consensus theory exemplifies centripetal theorizing while the three distinct moves of antifoundationalists-skepticism about value, conceptual relativity, and stability in meaning-represent centrifugal theorizing.

is nonetheless an exemplar of the interests of law and of the community through law, an exemplar that is capable of transcending the partial interests of a subgroup as reflected in a way of thinking that reflects domination of one subgroup by another. Critical writers question the possibility of such transcendence.

${ }^{50}$ Introductory essays by Dworkin and Tushnet illustrate the tendencies of theorists to identify questions of the bounds and nature of law with questions about the role of judges. See RONALD DWORKIN, A MATTER OF PRINCIPLE 9-32 (1985); MARK TUSHNET, ReD, WhITE, AND BluE: A CrITIGal ANalysis Of CONSTITUTIONAL LaW 1-17 (1988). 


\section{a. Consensus Theory}

The trajectory traced by the relevant recent writings on constitutional interpretation ${ }^{51}$ is deceptively simple. The expressed goal of many writers is a criterion for proper decisionmaking. Such theorists argue that a criterion is needed to constrain judicial license and to validate criticism of judicial reasoning. Accordingly, some argue that a correct understanding of judicial interpretation (of the rules of the practice) requires adherence to the intentions of the founders. ${ }^{52}$ Others try to show that interpretation is governed by "disciplining rules" that assure judicial objectivity. ${ }^{53}$ Still others describe a method for arriving at the "best interpretation" of tacit principles embodied in our constitutional legacy. ${ }^{54}$ The underlying assumption in each case is that the rules of the practice are capable of constraining judicial discretion and thus fostering a neutral, objective, or integrative approach to decision-making.

\section{b. Antifoundationalism}

Antifoundational skeptics reject this consensus position, arguing that the rhetoric of neutral rules obscures our understanding of a process that is altogether political. Accordingly, these theorists subvert the idea of objective rules by attacking assumptions about shared social values, individual impartiality, and fixed textual

${ }^{51}$ By "recent" I refer to the avalanche of writings since 1970 in constitutional theory. This includes, in the first generation of writers, the work of Ronald Dworkin, John Hart Ely, Michael Perry, Paul Brest, Laurence Tribe, Owen Fiss, and Richard Kay. These writers defend particular approaches to decision-making as constraints upon judicial license and as explicating the true meaning of constitutionalism. The range of approaches represented by these writers is wide, from original intent to various kinds of liberalism. In the 1980s, the flowering of critical theory in the work of many writers, including Mark Tushnet, Sanford Levinson, Catharine MacKinnon, Duncan Kennedy, Robert Gordon, Robin West, Joseph Singer, and Roberto Unger, represents a retreat from the claim that judicial decision-making is indeed constrained and that the idea of constitutionalism is rich enough to embrace principles reflecting the shared interests of all.

52 Raoul Berger is probably the most prolific theorist defending original intent. See RAOUl Berger, Government by JUdiciary: THE Transformation of the FOURTEENTH AMENDMENT (1977). A recent and eloquent defense of original intent theory is Richard S. Kay, Adherence to the Original Intentions in Constitutional Adjudication, 82 Nw. U. L. REV. 226 (1988).

${ }^{53}$ See Fiss, supra note 48, at 744-50.

54 See DWORKIN, supra note 36, at 225-75. For a succinct statement of Dworkin's position, see Ronald A. Dworkin, "Natural" Law Revisited, 34 U. FLA. L. REV. 165, 16673 (1982) [hereinafter Dworkin, Natural]. 
meaning.

While all of these antifoundational arguments have centrifugal impact, their scope and implications vary. The moral argument of these critics tracks what many see as common sense: the view that judges have and follow political agendas. The spectrum of political agendas embraces on the political left egalitarian and redistributive processes and goals, and on the right laissez-faire and libertarian ones. A particular judge may have a complex agenda, taking leftleaning positions on some issues and right-leaning ones on others. ${ }^{55}$ She may even be torn by conflicting approaches to a particular issue. The spectrum of political agendas is often described in terms of competing conceptions of liberalism, from a welfare state model with a broadly redistributive agenda to a laissezfaire model of minimal state intervention.

The conceptual argument maintains that partiality is unavoidable not only in social values but also in conceptual capacities. Thus, it impeaches the basis of liberalism, the idea of government as a neutral and non-interfering arbiter among persons with different schemes of preference. The argument says that noninterference in preference formation is an illusion because persons do not form preferences independently of the institutional and educative context that makes the existence of preferences and choice possible. ${ }^{56}$ Moreover, any such context embodies relationships of power and assumptions about value that shape the conceptual categories and language in which preferences are understood, expressed, and acted upon.

Accordingly, the conceptual argument continues, a communitarian description of the role of government and law must replace liberal assumptions. Communitarian theorists make disparate claims. One is that we must recreate a vanished or hypothesized time of shared social values, a time of consensus about the rules of the practice. A second claim is that one must seek to transcend the conceptual partiality induced by the social and institutional context that defines one's personal history. ${ }^{57}$ In embracing deconstructive

55 In contrast to this man-on-the-street description of judges as creatures of politics, Duncan Kennedy offers an attempt to characterize judging "from the inside." See Duncan Kennedy, Freedom and Constraint in Adjudication: A Critical Phenomenology, 36 J. LEGAL EDUC. 518 (1986).

${ }_{36}$ See MACKINNON, supra note 3, at 121-25; Gordon, supra note 3, at 102-13; West, supra note 2, at 81-90.

${ }^{37}$ Not all critical theorists who maintain the conceptual relativism argument end up advocating communitarianism. Nonetheless, the theme is widely supported and 
semantic or linguistic arguments, recent constitutional theory offers a third kind of antifoundational (or centrifugal) gesture in addition to the moral arguments against any possible consensus of social values within liberalism, and to the conceptual arguments against liberalism itself as neutrality. This third attack questions whether texts themselves-in expressing rules, goals, and values-have determinate meaning. ${ }^{58}$ If constancy of meaning across different hearers/interpreters is an illusion, then any shared understanding of rules is adventitious and unreliable.

The three antifoundational arguments erode the foundations of the metaphor of games. The moral attack on a liberal consensus theory maintains that the shared rules by which judges judge do not produce common answers to hard questions. The rules are at best rules of language and meaning by which judges recognize one another's justifications. The conceptual attack on liberalism as neutrality maintains that different subcommunities play by different rules with differing commitments, and that shared rules of language and meaning mask rather than bridge diversity. Finally, the semantic attack on language and determinate meaning, concludes that reliance on any determinate rules is itself an illusion. Thus at each level the metaphor of a game as a practice with shared rules erodes further, eventually to the vanishing point.

discussed by critical legal theorists and feminists. See TUSHNET, supra note 50; Symposium, The Republican Civic Tradition, 97 YALE L.J. 1493, 1493-1723 (1988); Joan C. Williams, Deconstructing Gender, 87 MICH. L. REv. 797, 836-43 (1989);.

58 Richard Kay summarizes this view in stating that

[some] critics emphasize that variability of meaning is a necessary consequence of the multiplicity of readers. Every act of interpretation is a shared enterprise between the text (and its author) and the reader. The consequences of that enterprise depend not only on what the text contains but on the outlook, expectations, and preconceptions of the reader. Interpretation must, therefore, vary from reader to reader, from era to era or from group to group.

Kay, supra note 52, at 237-38 (footnote omitted). See also FISH, TEXT, supra note 19, at 1-17 (tracing Fish's theoretical shift from the view that the text provides meaning and constrains interpretation to the theory that the text is a product of interpretation); id. at 97-111 (arguing that "literature" is not a formal set of criteria but rather is "made" by a community of readers). Writers align themselves on a spectrum according to their views about the degree of constraint imposed by the text, the reader's community, etc., as opposed to the degree of freedom and indeterminateness in reading. Gadamer and Fish both discuss the constraining impact of interpretive communities. See HANS-GeORg Gadamer, TRUTH AND METHOd 267-72 (1975). For a critique of "nihilistic" versions of this relativist thesis, see Dennis M. Patterson, Interpretation in Law-Toward a Reconstruction of the Current Debate, 29 VILL. L. REV. $671,680-82$ (1984). 


\section{c. Implications for Theory and Practice}

Consensus (centripetal) theorists who claim to find determinate constraints on judges by identifying original intent or evolving shared values take the point of view of enlightened participants of the practice and highlight the insider's understanding of the rules. As a result, they meld recommendations for the resolution of hard cases with theoretical analysis and commend particular justificatory schemes and outcomes to judges. ${ }^{59}$ By contrast, antifoundational (skeptical, centrifugal, deconstructive) theorists tend to take the perspective of outsiders to the practices they criticize. ${ }^{60}$ For example, they attempt to explain why the idea of a consensus is illusory.

Accordingly, moral skeptics, who question the availability of shared values, conclude that the rules of the practice (like those of many true games) insure that players will use competing strategies and have irreconcilable aims. ${ }^{61}$ Skeptics who stress the partiality of any conceptual framework speak from the point of view of outsiders and assert a conceptual gulf between the points of view of theorist and participant: the participant, as insider, is trapped within a perspective and constitutes reality from that perspective while the theorist, as outsider, characterizes all participant-perspectives as equally partial, and in this sense claims to transcend them. An even greater gulf exists between the linguistic skeptic, who claims that texts and utterances in general have no determinate meaning, and the participant, whose activity presumes that words communicate and justify decisions. ${ }^{62}$

The difficulties that any theory has in coming to terms with the relationship of participant and theorist reflect the complex, Janus-

${ }^{39}$ Dworkin, for example, argues that implicit in his theoretical analysis are ways of resolving hard questions about abortion, free speech, affirmative action, and civil disobedience. See DWORKIN, supra note 50, at 104-16 (civil disobedience), 293-331 (affirmative action), 335-97 (censorship, pornography, and freedom of the press); DWORKIN, supra notes 47, at 123-30 (abortion), 206-22 (civil disobedience), 223-39 (reverse discrimination).

60 This stance is complicated by the fact that antifoundationalists paradoxically argue that there "is no outside." This is an instance of the skeptical paradox so well described by Strawson. See infra note 68.

61 The extent to which this is true in a given community at a given time will vary with the issue and with the range of positions on the issue. There generally will be harmony on some issues.

62 The extent of the gulf depends, of course, on the relative degree of constraint the theorist is willing to concede to continuity of meaning over time, to stability of meaning within a community, etc. See supra note 58 and accompanying text. 
like role of judges as appliers of rules and interpreters/creators of rules. If judging is like a game, what role-that of rule-maker, umpire, or player-is performed by the judge? In true games, the distinction between participant and non-participant follows immediately from the rules. Theoretical discourse about the rules themselves, rather than about moves that apply the rules, is the activity of outsiders and not of participants. The fact that judges, who are obviously participants, engage in discourse about the rules and in applying the rules complicates the distinction between participant and theorist and underscores how problematic the metaphor of games is in this context. ${ }^{63}$

\section{Critique}

Each theoretical position on judicial interpretation is open to the criticism that it is counterintuitive. Do consensus theorists imagine that an analysis of the constraints on judging can make hard cases easy and displace disagreements that have survived as long as courts have existed? Such assurance has been and remains a jurisprudential sitting duck. ${ }^{64}$ On the other hand, the moral skeptic's tendency to sort out conflicting positions along a familiar political spectrum ${ }^{65}$ seems to belie the complexity and diversity of judicial reasoning. The conceptual skeptic's implication that each judge is cocooned within a conceptual scheme, one that presumes unquestioningly a particular allocation of power, entails despair ab

${ }^{63}$ See supra text accompanying note 46; cf. supra note 21 and text accompanying notes 21-24 (discussing the implications of adopting so-called internal or external points of view).

${ }^{64}$ For an acute critique of Dworkin's theory, see David C. Hoy, Dworkin's Constructive Optimism v. Deconstructive Legal Nihilism, 6 LAW \& PHIL. 321 (1987). See also Larry Alexander, Striking Back at The Empire: A Brief Survey of Problems in Dworkin's Theory of Law, 6 LAW \& PHIL. 419 (1987); Stanley Fish, Still Wrong After All These Years, 6 LAW \& PHIL. 401 (1987).

${ }^{65}$ Kennedy claims that "there are two opposed rhetorical modes for dealing with substantive issues, ... individualism and altruism." Duncan Kennedy, Form and Substance in Private Law Adjudication, 89 HARV. L. REV. 1685, 1685 (1976). Kennedy's description of the two modes fits some conceptions of the political spectrum defined by "right" and "left." In this sense, classic liberalism is individualistic and right-wing, whereas modern liberalism is collectivistic. My argument implicitly challenges Kennedy's claim that this particular political dyad, or pair of alternatives, is conceptually primitive. I claim that in addition to the metaphor of government as neutral mediator and the metaphor of government as incorporator and nurturer of value, other metaphors drawn from physics, psychology, history, etc., are equally available and primitive. The range of available metaphors seems in principle unlimited. 
initio toward the efforts of judges to reflect upon and effectively to transcend such limits. Finally, judges and all who use language presume in their actions that the linguistic skeptic is misguided and that meaning is communicable.

Each of these theories can be criticized for assuming that what can be said of some instances of judicial reasoning can be said for all. Some consensus theorists assume that if judges are constrained by history (original intent) in some cases, then history is equally relevant in all. ${ }^{66}$ Others argue that if there is a consensus of value, then cases in general are to be resolved by appeal to it. ${ }^{67}$ If judges are ever affected by conceptual bias, by non-neutrality, then they are generally affected in this way. If language is indeterminate, if communication is imperfect, it is generally imperfect. All four of these presuppositions homogenize judicial reasoning. All for that reason seem counterintuitive. ${ }^{68}$

My critique is sketchy and incomplete. It is intended not to dismiss consensus and skeptical theories, but to situate them by reference to their characterization of agreement and disagreement. Consensus theory maintains that disagreement is in principle eradicable. Skeptical theories hold that disagreement is deep and enduring. ${ }^{69}$ All of the theories reach these conclusions by taking

${ }^{66}$ See BERGER, supra note 52, at 363-72 (arguing that original intent should always be used as an interpretive guide).

67 See, e.g., DwORKIN, supra note 36; DwORKIN, supra note 47; Fiss, supra note 48 (discussing the notion of an "interpretive community" as central to his argument on the possibility of objective interpretation).

${ }^{68}$ Theorists often take a characteristic of some instances of reasoning and treat it as a characteristic of all reasoning. Everyone can easily summon up instances of values that are relative (variable across individuals), of concepts that reflect bias, of indeterminate language, or of cases in which adherence to historical intent is defensible. But universalizing these observations is not plausible. Not all values are relative in the same way; some values reflect variable preferences while others reflect universal needs. To call the latter "relative" is to remove the term from ordinary usage, and thus not to speak unequivocally. Similarly, the policies of Amnesty International do not reflect bias in the way that, for example, the policies of the State of Mississippi in 1961 did. To say that all policies reflect the biases of the empowered is, again, to give specialized meaning to "bias" and to use it equivocally. Some uses of language give rise to perceptions of ambiguity and to puzzlement; others do not. To say that both are "indeterminate" is to use the term equivocally, employing its ordinary usage in the first instance but not in the second. Cf. P.F. STRAWSON, INDIVIDUALS: AN ESSAY IN DESCRIPTIVE METAPHYSICS 106 (1959) ("So with many skeptical problems: their statement involves the pretended acceptance of a conceptual scheme and at the same time the silent repudiation of one of the conditions of its existence. That is why they are, in the terms in which they are stated, insoluble.")

${ }^{69}$ This view is also commonplace among political scientists. The special 
shortcuts, by assuming that certain generalizations about legal justification hold universally. Before devising a more complete critique of these theories, I shall offer an account of judicial agreement and disagreement that explains them in terms of the heterogeneity of justificatory strategies.

\section{B. Practices and Deliberative Practices}

To understand how consensus theorists and skeptics alike overlook essential features of legal reasoning and buy theoretical clarity at the cost of misdescription, we need to look at the heterogeneous character of legal justification and the scope of justificatory patterns that judges use to explain judgments. Doing so requires us to examine the more general idea of a practice and the narrower idea of a deliberative practice before applying the concept of a deliberative practice to judicial reasoning.

\section{Practices in General}

The concept of a practice is among the most useful (and controversial) tools of twentieth-century philosophy. ${ }^{70}$ An intuitive look at practices may begin with such nonlinguistic activities as driving or swimming. In each case, persons acquire skills or ways of proceeding that become habitual and unreflective. When we call such skills "second nature," we mean that, though they are socially and culturally grounded, such ways of proceeding become as much a part of us as our genetic endowment. ${ }^{71}$

contribution of critical theory is to give this assumption a conceptual or epistemological character-in reaction to the common disregard of questions of epistemological relativism in debates between positivists and naturalists. So long as the main concern of theory was the nature of law and so long as that issue was not reduced to the nature of resources for judging, epistemology was not of immediate concern. Once judges took center stage, epistemological questions could no longer be avoided.

70 The conception of philosophy as the examination of practices, preeminently linguistic practices, has come under sustained attack. For one of the earliest sets of critical articles, see CLARITY IS NOT ENOUGH: ESSAYS IN CRITICISM OF LINGUISTIC PHILOSOPHY (H.D. Lewis ed., 1963); $c f$. ESSAYS ON MORAL REALISM (Geoffrey SayreMcCord ed., 1988) (providing a moral realist view at odds with the practice conception, treating it as a form of conventionalism); REDRAWING THE LINES: ANAlytic Philosophy, Deconstruction, and LITERARy THEORY (Reed W. Dasenbrock ed., 1989) (examining the implications of the practice conception in reference to contemporary theories).

${ }^{7}$ One might distinguish swimming from driving by arguing that acts involving survival and locomotion in water are, to some extent, natural and spontaneousalthough they are not universal and although particular strokes must be learned. Driving, on the other hand, is wholly an adaptation to technology and in no sense is 
A habitual repertoire has distinctive features and distinctive ways of perceiving, feeling, and acting. A good driver makes judgments about road conditions and the disposition of other drivers, apprehends dangers, and acts accordingly. What she does unreflectingly can, however, be made conscious. ${ }^{72}$ Ordinarily, doing so is neither necessary nor appropriate.

A characterization of what is involved in having such a skill, in being a good driver, is at once descriptive and normative. The characteristics of a driver (in general) are distinguished only in degree from the characteristics of a good driver. To be able to identify driving is also to be able to tell good driving. Both thresholds are inherently vague. No clear and simple criterion distinguishes those who cannot drive from those who do so very badly. ${ }^{73}$ Similarly, not everyone will agree on the marks of very good driving. But the range of understandable disagreement is low.

\section{Linguistic Practices}

Some of our practices are primarily communicative (as driving obviously is not). And some of our communicative practices, by far the most important ones, are linguistic. Wittgenstein attends to such aspects of language as color-descriptions and expressions of pain. Just as driving is a skill that individuals acquire because a public practice, a shared activity, already exists, so too perceptions of color and distinctions among kinds of pain manifest the acquired skills of those who have been initiated into certain practices. ${ }^{74}$ Persons identify colors and pains to the extent that a place exists for

the repertoire of the behavior natural or spontaneous. Psychologists might regard all these observations as trivially true. Among some philosophers before Wittgenstein, such as Locke and Hume, the notion that the capacity to recognize objects and name them was natural and spontaneous, rather than part of a socially learned repertoire, was a basic tenet of epistemology. See 1 DAVID HUME, A TREATISE OF HUMAN NATURE 1-25 (1890, orig. 1739); 2 JOHN LOCKE, AN ESSAY CONCERNING HUMAN UNDERSTANDING 3-164 (Alexander C. Fraser ed., 1959) (1690). For Wittgenstein's criticisms of the natural and spontaneous capacity theory, see WITTGENSTEIN, supra note 22, at 2-10.

72 Perhaps unconscious repertoires of behavior cannot be made completely conscious. Consider the way one conveys attitude by facial expression, intonation, etc. Self-scrutiny can discover some dimensions of the repertoire but probably not all.

73 See Thomas Morawetz, The Philosophy of LaW 11-16 (1980) (noting as an illustrative example the conceptual difficulties in defining a knife).

${ }^{74}$ See WITTGENSTEIN, supra note 22, at 88-93, 95-104; see also LUDWIG WITTGENSTEIN, REMARKS ON COLOUR (G.E.M. Anscombe ed., Linda L. McAlister \& Margarete Schättle trans., 1977). 
the recognition of color and the expression of pain in the relevant practices of a culture. ${ }^{75}$

\section{Deliberative Practices}

These considerations about practices in general and about simple linguistic practices in particular have implications for more complex practices involving deliberation. A deliberative practice consists of discourse directed toward forming and defending judgments. Examples of deliberative practices are esthetic debate, moral reasoning, discussions about history, and judicial decisionmaking. The subject may be whether an object is beautiful, or whether an action is right, or whether an event is a turning point in history, or whether a plaintiff has a right to a favorable judgment.

All such debates have certain features in common. All involve widely shared activities and/or institutions in civilized societies. All involve abstract questions that have preoccupied persons throughout history and seem intractable.

\section{a. Understanding Disagreement}

All practices allow the possibility, indeed the inevitability, of idiosyncracy within shared ways of proceeding. Even though persons share a sense of what driving is, each driver has a personal style. Similarly, each of us has a distinctive way of using color language: I may tend not to discriminate among various shades of red; one friend may sharply distinguish scarlet and crimson; another friend may use these two terms in a distinctively different way. ${ }^{76}$

In deliberative activities, this diversity within shared mutually understood ways of proceeding is especially significant. No two persons have the same history or have the same dispositions. Some are more credulous than others, more perceptive, more doubting, more impulsive; some are better versed in history, some in physics,

${ }^{75}$ Some philosophers have seen this suggestion as revolutionary and counterintuitive. The philosophical assumption of most empiricists has been that the domain of private experience is fully configured and that the public arena of language is merely a set of conventions and labels attached to the distinct elements of private experience. But Wittgenstein challenges this assumption. He asks us to reflect on what it could be like to experience a color for which a place was not already prepared in the experiential realm shared with others.

${ }^{76}$ Ordinarily, the shared practice offers all of us means for discovering and sorting out our divergent ways of proceeding in those relatively rare cases in which it matters to do so. To that extent, variation exists and is discoverable within a shared context. 
some in psychology; and some are generally ignorant. Much more importantly, each has a characteristic way of reasoning that represents an interpretive orientation to the world, a way of making sense of the phenomena of experience by giving order to the many domains of knowledge and opinion in which she or he participates.

Consider the diversity of reasons given to justify and explain esthetic judgments. One person may offer psychological grounds for finding something beautiful. Another may refer to inherent properties of the object itself. Yet another may look to the ways in which the object expresses the intentions of the artist and to the quality of those intentions. A fourth may appeal to the social and political function of the object in assessing esthetic worth. ${ }^{77}$

Other deliberative practices can be broken down in a similar manner. One historian will use the influence of ideas as the explanans that unlocks historical change; another will look to economic motives and events; still another will stress the charismatic influence of leaders. ${ }^{78}$ In moral discourse, one theorist will see altruistic utilitarianism as offering the most coherent account of moral judgment; another will see psychologistic or hedonistic utilitarianism as basic; a third will argue that moral reasoning is essentially deontological. ${ }^{79}$

\section{b. Agreement and the Bounds of Practice}

It is as important to see what draws participants in deliberative practices together as to see what separates them. Even when they disagree, participants recognize and understand each others' argumentative strategies. They share a sense of what reasons are relevant to the common discourse. Discussing beauty, they may

${ }^{77}$ For a recent collection of articles on various esthetic theories, including cognitivism, representationalism and expressionism, see MODERNISM, CRITICISM, REALISM (Charles Harrison \& Fred Orton eds., 1984).

${ }^{78}$ See Patrick Gardiner, The Nature of Historical Explanation 65-112 (1952) (examining historians' method of explaining events); see generally SIDNEY HOOK, THE HERO IN HISTORY (1943) (arguing that historical events are primarily the product of extraordinary individuals).

${ }^{79}$ For recent and thought-provoking discussions of metaethical questions, see THOMAS NAGEL, THE VIEW FROM NOWHERE 164-88 (1986) (analyzing reasons for departing from the general goal of objective ethical criteria); BERNARD WILLIAMS, ETHICS AND THE LIMITS OF PHLOSOPHY 30-93 (1985) (evaluating the contribution of philosophy to coherence in ethical reasoning); see also C.D. BROAD, FIVE TYPES OF ETHICAL THEORY (1934) (explaining and criticizing the ethical theories of Spinoza, Butler, Hume, Kant, and Sidgwick); ALASDAIR MAcINTYRE, WHOSE JUSTICE? WHICH RATIONALITY? (1988) (arguing for the possibility of cross-cultural rationality in ethics). 
consider symmetry and asymmetry, balance and imbalance, representational aspects of the object, context, or purpose. They will not consider relevant whether the artist had a short life, whether her name began with a vowel, or whether the object or performance is privately financed. These observations may seem obvious, but only because they are so familiar, only because they are "second nature." Each participant can generally anticipate the moves that others will make. ${ }^{80}$ The practice consists in the recognition of a family of reasoning strategies that allow for a spectrum of judgments.

Thus, it is not the case that anything counts. Just as in driving or in identifying colors, the publicly shared understanding of what moves are comprehensible ways of proceeding circumscribes the practice and makes it possible. To try to imagine a practice in which any act by someone sitting in a driver's seat counts as driving or a practice in which any use of a color word is meaningful is to imagine the impossible.

In deliberative practices, each participant will to some extent take account of the reasons offered by others by trying to accomodate them within her own favored strategy. ${ }^{81}$ The utilitarian will generally have considered and, to her satisfaction, explained away

${ }^{80}$ It seems to me this is what Wittgenstein had in mind when he said:

80. The truth of my statements is the test of my understanding of these statements.

81. That is to say: if I make certain false statements, it becomes uncertain whether I understand them.

....

83. The truth of certain empirical propositions belongs to our frame of reference.

149. My judgments themselves characterize the way I judge, characterize the nature of judgment.

WITTCENSTEIN, supra note 1, at 12e, 22e. Wittgenstein's insight seems to be that any practice allows certain justificatory moves and not others, and that such other moves are necessarily unintelligible and mark those who make them as nonparticipants, mark their comments as nonsense. This is true of all language-games, true of all discourse: every language-game is comprised of generally understood rules of relevance. Intelligibility of any kind of discourse depends on shared conceptions of relevance and irrelevance. Those who offer irrelevant evidence, justification, etc., are speaking nonsense as far as the shared practice goes.

81 This is not to say that one participant may not simply be dismissive of others. But the justifications offered by that participant are defective or incomplete unless she can take account of others' reasons either by showing why her way of deciding is superior or by modifying her way of deciding to accommodate and assimilate what she finds valuable in the alternatives. 
non-utilitarian strategies and will have a favored account of their appeal; the non-utilitarian will approach the utilitarian in the same way. The person who gives psychological explanations for economic phenomena will have ways of accounting for and rejecting the opposite approach, and vice versa. Judges who find an evolving consensus of values can explain why others find a different consensus or none at all, and can argue why the others are wrong. Thus, an essential part of each participant's way of proceeding will be a strategy for incorporating or dismissing the favored strategies of others. And each in turn will recognize and anticipate such moves as part of the ongoing practice.

Equally essential to each participant's way of proceeding is the recognition of her strategy's limitations. First, she will continually encounter-and expect to encounter-new alternatives, new strategies and new ways of thinking that she has not yet considered. Second, she will appreciate that her strategy does not offer a "transcendental" argument which subsumes the strategies of others but one which is instead on a par with theirs: for each move she makes to answer or accommodate others, these others can in principle make a similar move. The expectation is of perpetual dialogue, not final solutions.

\section{c. Discourse and Debate}

The diverse strategies that make up a deliberative practice compete because there is no natural order of precedence among categories of facts, among categories of reasons and justifications. Categorical reduction can occur in many directions. For example, some theorists explain political and economic phenomena by reducing them to psychological patterns. Other theorists argue that social experience is not reducible to individual psychological categories and that economic phenomena are based on idealized models and not psychology. The claim that all phenomena are explainable through the hard sciences of physics and chemistry is now widely rejected along with the supposed superiority of microscopic to macroscopic explanations. ${ }^{82}$ Reductionism in aesthetics does not fare better. Appeals to the inherent features of a work of art are neither more nor less basic a mode of justification

82 Peter Winch, The Idea of a SOCIAl ScIEnce: AND ITS RElation to PHILOSOPHY 8-9 (1958) (arguing that scientific methods are not capable of answering the philosophical question of "what is real?"). 
(in esthetic reasoning) than appeals to the creator's intentions or to the work's gestalt. ${ }^{83}$

It is therefore up to the individual to choose among available competing forms of explanation and to favor or reject reductionist arguments. Convictions about relations among categories of knowledge run deep. Try to shake the conviction of one who holds that morality can "ultimately" be explained by chemical events in the brain, or the conviction of someone who rejects this. Try to dispel the reductionist approach of someone who favors a psychological account of, say, the attractions of fascism-or try to instill such an approach in someone who thinks it is simplistic and banal. ${ }^{84}$ In defending one's own judgment in a particular case, one is also defending one's style of judgment, one's way of ordering the data of experience to give some kinds precedence. The attempt to convince others is not only an attempt to make them agree with one's own conclusions but also an attempt to bring them around to one's style of judgment. ${ }^{85}$

\section{d. Persuasion}

The persuasive attempts of each participant are not, as one might think, doomed. To say that each participant has a particular way of proceeding in reasoning is not to say that she is condemned to repeat the same moves forever. Individual participants differ not only in judgments and in ways of reaching those judgments, but also in their susceptibility to persuasion, and to considering and adopting other points of view and other strategies. The practice itself, as a collection of strategies mutually recognized by participants, evolves. Over time some strategies gain currency while others go into temporary or permanent remission. Particular styles of moral reasoning, of thinking about history, or of judging what the appropriate role for government gain currency and then fade. ${ }^{86}$

${ }^{83}$ See supra text accompanying note 77.

${ }^{84}$ A good example is the controversy that followed publication of HaNNAH ARENDT, EICHMANN IN JERUSALEM: A REPORT ON THE BANALITY OF EVIL (1963). See Hannah Arendt, Major Twentieth Century Writers, Aug. 1991, available in LEXIS, Nexis Library, Allbio File (noting that Arendt's "subtle arguments provoked highly emotional responses" among critics).

${ }^{85}$ The impulse toward harmonizing or reconciling one's way of proceeding with others' may be overridden by practical concerns. A judge will sometimes be content for others to concur with her in result even if the result is reached on different grounds.

${ }^{86}$ For example, emotive approaches to morality, "great man" theories of historical 


\section{Judicial Decision as a Deliberative Practice}

The general description of deliberative practices highlights the heterogeneity of the various strategies of reasoning that constitute such practices. Deliberative practices encompass two kinds of heterogeneity.

First there is heterogeneity within an individual's way of proceeding. A given person will solve different problems in different ways-with evidence drawn from whatever realms of experience seem appropriate. A judge may draw on moral arguments in some cases, historical or economic arguments in others. ${ }^{87}$ Some judgments will reflect one's deepest convictions, while others will reflect less fundamental beliefs.

Second, there is heterogeneity among those making judgments. Each judgment-maker has her own idiosyncratic ways of ordering experience within the mutually recognized bounds of what is intelligible in the deliberative practice.

Legal theorists have not adequately taken into account the complex nature of judicial decision-making. This is true of consensus theorists as well as antifoundational skeptics. The latter's references to value schemes and conceptual systems oversimplify and exaggerate the sources and nature of disagreement by closeting them into discrete value systems or conceptual frameworks. ${ }^{88}$

Thus, theorists do not look deeply enough into the sources and kinds of disagreement among judges. Certainly, theorists deal with the brute fact that judges reach different results. Theorists also take into account that judges who vote the same way may disagree in

influence, mechanistic explanations of behavior, and civil libertarian theories of government all move on and off center stage. These theories may become prevailing modes of thinking, reasoning, and justifying or they may be widely rejected.

${ }^{87}$ To do so is not to be inconsistent. Such a judge may be fairly accused of inconsistency only if she commits herself to inconsistent propositions or if she chooses modes of justification arbitrarily, with no principled manner of selection. Only a theoretical commitment to homogeneity would lead one to expect judges to decide every case on historical grounds (original intent) or on economic grounds. Such theoretical commitments can be defended. See RICHARD A. Posner, ECONOMIC ANALYSIS OF LAW 15-23 (2d ed. 1977) (defending economic efficiency as the ultimate criterion); Kay, supra note 52, at 236-92 (defending deference to historical intent as inherent in constitutionalism). Such theoretical commitments to homogeneity, however, are notoriously vulnerable to counterarguments.

${ }^{88}$ See Kennedy, supra note 65, at 1685; West, supra note 2, at 81-90 (arguing that the "male legal culture" frames its justificatory arguments in response to men's hedonic lives and that a different and alternative conceptual framework is offered through an understanding of women's hedonic lives). 
their justificatory reasoning. One judge may argue that stopping drivers at random to check for intoxication implicates the fourth amendment, but is justified by exigency and is a minimal infringement. ${ }^{89}$ Another judge reaching the same decision may argue that stopping drivers at random does not implicate the fourth amendment at all.

Theorists characteristically ignore the fact that judges disagree in a third and much more interesting way: in their ways of structuring information-counting some kinds of propositions as evidence for other propositions and resting their arguments on one kind of proposition rather than another because the former is conclusive in their particular way of understanding experience. A judge may cite social conditions as ultimate reasons for a decision, for example the fact that one class of individuals is systematically disadvantaged. ${ }^{90}$ Another judge may claim that psychological effects on individuals are of primary importance. ${ }^{91} A$ third judge may cite economic facts as ultimate, for example the fact that the more-or-less efficient market distribution of goods or benefits in society will be compromised or curtailed. ${ }^{92}$ Yet another will look

${ }^{89}$ See, e.g., Stark v. Perpich, 590 F. Supp. 1057 (D. Minn. 1984) (holding that stopping vehicles at a roadside drunk driving survey constitutes a seizure under the Fourth Amendment, but that such seizures may still be permissible under certain circumstances); Garrett v. Goodwin, 569 F. Supp. 106 (E.D. Ark. 1982) (same, but also dismissing Fourteenth Amendment considerations); Little v. State, 479 A.2d 903 (Md. 1984) (same).

90 See, e.g., Bowers v. Hardwick, 478 U.S. 186, 219 (1986) (Stevens, J., dissenting) (stating that a state's justification for selective application of a statute must be supported by a "neutral interest" and not just a mere dislike for the disfavored group); Yick Wo v. Hopkins, 118 U.S. 356, 373-74 (1886) (holding that the result of systematic denial of permission to Chinese people to carry on businesses demonstrated a violation of the Equal Protection Clause of the Fourteenth Amendment).

91 See, e.g., Bowers, 478 U.S. at 205 (Blackmun, J., dissenting) (claiming that "individuals define themselves in a significant way through their intimate sexual relationships with others" and for the Government to dictate the norms of sexual conduct would have severe psychological implications for the individual citizen); Brown v. Board of Education, 347 U.S. 483, 494 (1954) ("To separate [schoolchildren] from others of similar age and qualifications solely because of their race generates a feeling of inferiority as to their status in the community that may affect their hearts and minds in a way very unlikely ever to be undone.").

92 See, e.g., POSNER, supra note 87 , at 525 (stating that "although there are pecuniary gains to trade between blacks and whites ... by increasing the contact between members of the two races such trade imposes nonpecuniary, but real, costs on those members of either race who dislike association with members of the other race"). Wrongful birth cases also illustrate judges' differing strategies in finding moral or economic modes of justification relevant and decisive. See, e.g., Ochs v. Borrelli, 445 A.2d 883, 885 (Conn. 1982) (focusing on the economic injury caused by physician's negligence); Cockrum v. Baumgartner, 425 N.E.2d 968 (III. App. Ct. 1981) 
to political effects, assessing the likelihood that participation in government and the enjoyment of the benefits of democracy will be diminished. ${ }^{93}$ Still another may look to the values or principles deliberately implanted by the founders of the Constitution and will take as ultimate the importance of adherence to those principles. ${ }^{94}$

\section{Disagreement Among Judges}

One may address the complexity of a deliberative practice by taking note of the different, mutually recognized justificatory strategies that it embraces, different ways of ordering categories of knowledge or of using modes of explanation. One can also describe this complexity as wholly individualized, since each individual judge will have personal ways of juxtaposing and relating justifications drawn from her beliefs. Her strategies of reasoning will necessarily differ, at least in some ways, from those of each of her colleagues. No two judges will write exactly the same judicial opinions. Each will have different starting and finishing points for argument, different ways of deciding what is the explanans and what is the explanandum. ${ }^{95}$

\section{The Bounds of Judicial Disagreement}

Why and how does debate among judges persist in the face of this structural bias against agreement and harmony? One must remember what binds judges into a shared practice as well as what is personal and idiosyncratic.

First, any judge understands and anticipates that other judges

(in the case of an unwanted birth, finding that "the [emotional] rewards of parenthood should not be allowed in mitigation of rearing costs [damages]"), rev'd 447 N.E.2d 385 (Ill. 1983); Berman v. Allan, 404 A.2d 8, 14-15 (N.J. 1979) (apparently weighing moral and economic considerations against each other).

93 These concerns may be seen as central in a wide array of opinions. John Hart Ely has argued at length for their centrality. See ELY, supra note 29, at 135-99.

94 See cases and examples cited approvingly by Berger and Kay, supra note 52.

95 An important implication of my analysis is that there is no sharp or clean distinction between facts and values. The justificatory arguments of individuals include both facts and values, as well as intricate logical relationships among factual and value-based beliefs. For example, certain "factual" convictions about how persons are motivated, how they are affected by adversity, and how power relationships are perceived and perpetuated will (in conjunction with other premises and other beliefs) lead to certain "value" conclusions about what is fair and unfair in the regulation of such persons' lives. Convictions about fairness or justice or mercy-all of them "values"-may serve as premises or as conclusions of justificatory arguments. The same multiple roles are assumed by "facts." 
will have different patterns or styles of reasoning. More importantly, she understands that only certain patterns are intelligible as being within the practice. Thus a judge who decides cases in favor of the taller party, by reference to astrological projections, or by deferring to the ambassador of Lichtenstein would be intelligible in the sense that one could anticipate her responses but not intelligible as a participant in the practice of judicial decision-making. ${ }^{96}$

The practice involves a family of ways of structuring and ordering relevant evidence for decision-making. Each judge recognizes that other judges reason in certain ways, recognizes how they reason, and can give some account of why they reason as they do. The practice is bounded not by a single shared style of reasoning but by familiar, if unspecifiable, criteria for the kinds of reasoning that count. In the absence of such criteria, the practice would fall apart. Yet the criteria are malleable, and the line between included and excluded ways of thinking and of justifying decisions is not sharp. ${ }^{97}$

\section{The Driving Force of Judicial Persuasion}

The mutual recognition of permissible styles of justification does not sufficiently explain the persistence of deliberation among judges. When persons recognize that others have different ways of arriving at truth, that others favor economic or psychological or moral arguments, they continue to deliberate. Why do they persist?

${ }^{96}$ See supra note 81 and accompanying text.

97 Obviously such criteria evolve; what counts as acceptable, recognizable style or content changes over time. References to natural, inalienable rights "under God" may have been an acceptable mode of justification in the early nineteenth century. The use of natural law in contemporary opinions is more covert and wears the guise of fundamental rights explained in terms of familiar social facts and substantive due process. See, e.g., Moore v. City of East Cleveland, 431 U.S. 494, 503-04 (1977) (stating that constitutional protection of the sanctity of the family is not confined to an arbitrary boundary drawn at the limits of the nuclear family, and that limits on substantive due process should be drawn from basic societal values); Roe v. Wade, 410 U.S. 113, 152-53 (1973) (concluding that the right to privacy existing "under the Constitution" encompasses a woman's decision to terminate her pregnancy); Griswold v. Connecticut, 381 U.S. 479, 486 (1965) (concluding that the institution of marriage confers upon individuals a right of privacy "older than the Bill of Rights"). Evolving notions of what is expected and understood as the appropriate content of justification are even more clearly marked. Efficiency of distribution of resources has come to be treated as a covert but ultimately political value by some judges, see POSNER, supra note 87, at 415 (stating that "when judges are the makers of the substantive law the rules of law will tend to be consistent with the dictates of efficiency"), a mode of justification unknown and unanticipatable a generation or more ago. 
What kinds of success do they hope for?

The answer seems to lie in the stake that participants have in their ways of thinking, in their ways of proceeding within the practice. The participants themselves see what they are doing not simply as optional verbal gestures but as manifestations of the process of understanding the world-understanding why events occur, what purposes they serve, and what goals are worth serving. This is true in judicial debate as in all other cognitive and deliberative activity.

One judge, for example, may see economic events and economic motives as the operative levers of human and social action. For the world to be intelligible to her, she will not only describe events in accord with this commitment but will also try to persuade others to see the world in this way. The fact that others do not see the world this way is for her a recalcitrant experience, not just one of several recognized options. At the same time, she recognizes that a different judge will describe things and justify opinions differently, and she will feel committed to move others to understand and adopt her explanatory strategies, her ways of making sense of the world. But she recognizes that there are no agreed-upon or neutral standards of justification, no meta-game wherein she can justify once and for all her way of thinking. ${ }^{98}$

Each individual will hold certain convictions as basic and unshakable, as criteria for weighing the importance of other reasons and justifications. One judge or commentator will see a system that perpetuates any kind of racial discrimination as prima facie unacceptable. ${ }^{99}$ Another, believing that freedom to pursue economic goals is essential to any system of liberty and autonomy and that certain groups have been denied this freedom, may view discrimination as justified in some cases. ${ }^{100}$ Yet another may see

98 This point is controversial. Any theorist who claims that a particular method or mode of justification-such as original intent-is analytically the only correct method and is implied by the idea of constitutionalism, and any theorist who similarly claims to have identified a value to which all other values are reducible, e.g. economic efficiency, will reject this conclusion. My suggestion is that no method exists to validate such competing claims of correctness.

${ }^{99}$ See, e.g., City of Richmond v. J.A. Croson Co., 488 U.S. 469, 520 (1989) (Scalia, J., concurring) ("I do not agree ... with [the Court's dicta] suggesting that, despite the Fourteenth Amendment, state and local governments may in some circumstances discriminate on the basis of race in order (in a broad sense) 'to ameliorate the effects of past discrimination." ).

${ }^{100}$ See, e.g., id. at 529 (Marshall, J., dissenting) (stating that "the Richmond City Council has supported its determination that minorities have been wrongly excluded 
the essence of constitutionalism in preserving the limited role of the federal government as envisaged in the Federalist papers and the debates among founders. ${ }^{101}$ For a fourth, a perception of our society as involving and perpetuating an invidious social structure may determine what results can and cannot be justified. ${ }^{102}$

It is hard to overestimate the interest any person has in her way of making sense of experience, solving hard questions, and making judgments. One clings to modes or styles of thinking more tenaciously and profoundly than one does to particular opinions. ${ }^{103}$ It is more vital to one's continuing identity to believe, for example, that psychological or sociological data are the tools by which issues are resolved than to cling, come what may, to any particular judgment that such data yield. ${ }^{104}$ Thus, debates within deliberative practices are perpetuated by the need to assert both solutions to hard and disputed questions and particular ways of arriving at such solutions. The attempt to persuade others to "see" the world in the same way as one sees it oneself is parasitic upon

from local construction contracting. . . . These are precisely the types of statistical and testimonial evidence which, until today, this Court had credited in cases approving of race-conscious measures designed to remedy past discrimination.").

101 See, e.g., Paul BRest \& SANFord Levinson, Processes of Constitutional DECISIONMAKING 422 (2d ed.1983) ("After examining the debates in the Thirty-ninth Congress, [Raoul Berger] concludes that the adopters of the Fourteenth Amendment merely intended to ensure the constitutionality of the Civil Rights Act of 1866 and that Brown and almost all other Supreme Court decisions under the Fourteenth Amendment are incorrect." (citing BERGER, supra note 52, at 10)).

102 See Brown v. Board of Education, 347 U.S. 483 (1954)

103 Wittgenstein focuses attention on the importance to the individual of certain ways of reasoning:

559. You must bear in mind that the language-game is so to say something unpredictable. I mean: it is not based on grounds. It is not reasonable (or unreasonable).

It is there-like our life.

$\cdots$

608. Is it wrong for me to be guided in my actions by the propositions of physics? Am I to say I have no good ground for doing so? Isn't precisely this what we call a 'good ground'?

609. Supposing we met people who did not regard that as a telling reason. Now, how do we imagine this? Instead of the physicist, they consult an oracle. (And for that reason we consider them primitive.) Is it wrong for them to consult an oracle and be guided by it?-If we call this 'wrong' aren't we using our language-game as a base from which to combat theirs?

....

616. Why, would it be unthinkable that I should stay in the saddle however much the facts bucked?

WITTGENSTEIN, supra note 1 , at $73,80-81$.

${ }^{104}$ See id. 
the habit of giving structure to one's own experience, of deploying one's strategies of thinking.

\section{The Grounds of Persuasion and Change}

These strategies are recursive in the sense that they include the possibility, virtually the certainty, of self-modification through understanding and continually reconsidering the strategies of others. This prospect of evolving exists both for the individual and for the shared practice as a whole. What seems false or unacceptable to a person at one time may come to be a central truth by which other claims are judged. ${ }^{105}$ For the deliberative practice as a whole, some precepts and justificatory patterns that seem revolutionary at one time may be widely regarded as common sense a generation later. The role of privacy and autonomy in interpreting constitutional rights is just one such example. ${ }^{106}$

\section{Immersion in Practice as an Obstacle to Theory}

The question of whether judges are playing by the same or different rules when they disagree and offer incommensurable justifications is therefore oversimplified and nonsensical. On the one hand, judges recognize and are influenced by each other's moves. They share standards of relevance and recognize each other's ways of reasoning as variant forms within a shared practice. On the other hand, they go about thinking and reasoning in different ways. They have a stake in their own ways of thinking simply because these are their ways of thinking and making sense of experience.

They are participants in the same deliberative practice and yet they participate differently. The game metaphor fails because it is not illuminating to view these characteristic ways of ordering experience as a matter of following rules. Rules, even when they

105 Wittgenstein (writing in 1948-50) speaks of the inconceivability of any person getting to the moon or of any person not having two parents. Id. at 36,37 .

${ }^{106}$ See, e.g., Roe v. Wade, 410 U.S. 113, 152-53 (1973) (tracing development of the Court's concept of a right to privacy); Griswold v. Connecticut, 381 U.S. 479, 484 (1965) (discussing the growth of privacy "penumbras" around specific guarantees in the Bill of Rights). Consider also the example of the pattern of analysis and justification inspired by footnote four in United States v. Carolene Products Co., 304 U.S. 144, 152 n.4 (1938), which raised the question of "whether prejudice against discrete and insular minorities may be a special condition" in applying the general prohibitions of the Fourteenth Amendment. See, e.g., ELY, supra note 29, at 148-70. 
are second nature, can be made completely the objects of consciousness and, hypothetically, the objects of choice. One can imagine alternative rules for playing baseball or for describing colors and say to oneself, "These are the rules that I choose."107 But a way of thinking and experiencing is not a set of rules. It is an evolving way of thinking, a way of proceeding in which one has a stake and from which one can abstract oneself only provisionally, only tentatively. ${ }^{108}$

The sense in which judicial reasoning is a shared practice is captured by the way in which it has aspects of practices in general. The first aspect is the public character of practices. A mode of thinking, feeling, and speaking must already be generally shared within the culture before it can be appropriated by the individual. It must be present to be learned. Whatever diversity exists in possible ways of thinking and feeling is a publicly shared and mutually acknowledged diversity. ${ }^{109}$

The second aspect is individuality. Since each person has an individual history, her ways of feeling, thinking and expressing herself will reflect that personal history. ${ }^{110}$ She will create her personal variation on shared themes. Even judges who share a commitment to, for example, originalism or social equality as methodological constraints in decision-making, will carry out such reasoning in distinctively personal ways.

The third aspect is immediacy. A deliberative practice is not simply a way of using language or a method of moving from evidence to conclusions. It is a way of being in touch with reality, a way of giving shape and order to experience. ${ }^{111}$ To say it is

${ }^{107}$ Unless one generates a community of fellow-users of the new rules, the rules are useless for communication or other forms of action. See WITTGENSTEIN, supra note 22, at 75-95 (discussing the difficulties of conceiving of a private language).

${ }^{108}$ See FISH, NATURALLY, supra note 19, at 436-67 (discussing various processes of self-critical thinking).

${ }^{109}$ Nonetheless, creativity and innovation are possible insofar as each person puts received elements together in unique and unforeseeable ways, ways that may come to resonate within the community. Creativity is possible and explicable within legal doctrine just as it is within the so-called creative arts.

${ }^{110}$ See STRAwSON, supra note 68, at 41 (stating that " $[t]$ he principles of individuation of [private] experiences essentially turn on the identities of the persons to whose histories they belong").

111 In other words, the classic philosophical confrontation between coherence and correspondence theories of linguistic meaning and truth is, for my purposes, accommodated by observing that coherence accounts make sense insofar as there is no realm of objects other than the objects of experience and language, and that those objects are experienced as given (and in that sense as real). 
immediate is not to say that it is unchangeable. Becoming selfconscious of one's distinctive way of ordering reality may be a precondition of such change. ${ }^{112}$ Thus, a judge may surely understand herself as an originalist, for example, or as believing that certain social goals "make more sense" than all others. ${ }^{118}$ And she may question that distinctive way of ordering beliefs and change her ways of thinking. At the same time, she cannot abstract herself altogether into a position of indifference or into a sense that her way of thinking is, in the end, arbitrary. ${ }^{114}$

The immediacy of our practices of reasoning has an important implication. Inevitably, we deliberate not about how we see things but about how things are. Since we are within a frame, we lose sight of it as a frame. But we cannot forget it altogether, aware as we are that other persons have other frames. This means that any philosophical reflection about reasoning sensitizes us to a kind of tension between the certainty that attaches to what is most familiar, to the ways of thinking that are second nature, and to the sense that such certainty is ungrounded. Others with a different stake in reality-with other moral, religious, scientific certainties-and with different ways of thinking may be fellow conversants in our practices.

Any adequate theory of legal reasoning must address the consequences of viewing judicial reasoning as a deliberative practice. It must take account of both the heterogeneity of justification and the idiosyncratic character of individual strategies of justification. Even more importantly, it must take account of the tension between the role of practitioner and theorist-a tension not reducible to roles, to removing one hat and putting on another. Because engaging in a deliberative practice involves having convictions about reality and explanation, the practitioner asking theoretical questions can never bootstrap herself out of the tension and into a posture of neutrality or indifference about those convictions. A theorist who pretends she can disables herself from describing law adequately. ${ }^{115}$

Failure to understand judicial reasoning as a deliberative

112 See FISH, NATURALLY, supra note 19, at 141-60 (discussing change within "interpretive communities").

113 This description emphasizes that values are experienced as given, or incumbent on one, rather than as chosen.

114 See supra text accompanying note 98; see generally HUME, supra note 71, at 181218 (discussing the interplay between passion and will).

115 See infra Part IV. 
practice colors the contribution of both older jurisprudence, characterized by debates about legal positivism, and newer jurisprudence, characterized by the skeptical claims of antifoundationalists. Thus, the idea of judging as a deliberative practice can bridge the preoccupations of old and new jurisprudence.

\section{Legal Positivism and LaW as a Deliberattve Practice}

\section{A. Positivism and Judging}

Some of the main claims of legal positivism are incompatible with seeing law as a deliberative practice. However, a critique of positivism from this standpoint yields modifications that turn positivism into a stronger, more compelling theory of law. In order to assess this new strength it is necessary to identify the salient aspects of positivism.

\section{Positivism and the Identification of Law}

The still-evolving debate between positivists ${ }^{116}$ and their critics has centered on how judges identify law. ${ }^{117}$ The question of what law is and how it is to be identified is also a question about the limits of law. When does law run out? When does a judge exhaust her resources for identifying law and move beyond those limits? ${ }^{118}$

116 Legal positivism, like all philosophical "isms," refers to a family of views and positions. H.L.A. Hart and Joseph Raz are the most influential recent legal positivists. Commenting on "the elusive meaning of "positivism', "Raz describes its controversies with nonpositivists as a function of the identification of law, the moral value of law, and the meaning of key terms within legal discourse. JOSEPH RAZ, THE AUTHORITY OF LAW 37 (1979).

Note in this context that "the identification of law" can have several meanings since ordinary citizens, judges, and attorneys all need to identify law and do so in different ways.

117 The background assumption of these debates seems to be that judges are at the fulcrum of decision-making and of debate within the legal system and have as their job the identification of law even when that job is most difficult. Citizens can decline to make judgments in hard cases and attorneys can prepare briefs on both sides of a question, but judges must choose and justify their choices.

The fact that both positivists (for instance, Hart and Raz) and their critics (such as Dworkin) explain the identification of law by observing the behavior and discourse of appellate judges can be explained in a different way. Judges have been recognized in the history of jurisprudence as having the most controversial role of various legal actors. Legislators uncontroversially have the task of creating law. Attorneys and citizens have the burden of obeying the law and working within it. But judges are variously seen as applying the law and/or creating it.

${ }^{118}$ At its inception, legal positivism was not explicitly a theory about the identification of law by judges so much as a theory about the nature of law tout court. 
Whatever their differences, positivists address the problem of identifying law by emphasizing the importance of distinguishing "law as it is" from "law as it ought to be." is that the process of identifying the law is separate conceptually from the process of projecting aspirations for what the law might become and the goals it might serve. The first process uses formal criteria to identify the events of law creation. The second process uses moral reasoning, prudential reasoning, and other kinds of normative argument to consider ways in which the law might change in the future.

\section{Raz's Positivism}

Joseph Raz preserves this distinction when he identifies the "sources thesis" as the essence of legal positivism. ${ }^{120}$ To say that one identifies law by resort to formal criteria is to say that one identifies law by ascertaining whether particular law-creating events occurred. One looks, therefore, to social facts. Justificatory arguments play no part in the identification process because law, duly created, stands as law regardless of any justificatory arguments offered in its favor or in criticism. ${ }^{121}$

Early positivists tied law to power, suggesting that the legal order is established when rules are imposed by those who have stable (political) power over those who lack such power. John Austin, for example, represents law as commands backed by sanctions. The capacity to enforce sanctions and to make the threat of sanctions effective depends on power. One aspect of a legal order, according to this account, is that the rules express the wishes of the commander. See JOHN AUSTIN, THE PROVINCE OF JURISPRUDENCE DETERMINED ETC. 9-33 (Isaiah Berlin et al. eds., 1954) (1832). Such wishes may be indefinitely variable in their content. They may or may not coincide with the interest of the governed. They may in fact harm the governed in serious and unjustifiable ways.

H.L.A. Hart's positivistic account of law does not depend on particular assumptions about the relative power of individuals. See HART, supra note 21, at 1-25, 49-76. Austin's account, based on power assumptions, can not explain how law could bind all individuals, authorities as well as citizens, or how law could exist in a system in which power rested ultimately with the population at large, e.g. the electorate. Hart offers an institutional theory of law whereby a legal system exists whenever stable institutions promulgate rules that establish order in the society at large. The rules are of two kinds, primary rules that order the lives of all citizens and secondary rules that instruct and empower authorities in making, interpreting, and executing the rules. See id. at 77-96.

${ }^{119}$ H.L.A. Hart, Positivism and the Separation of Law and Morals, 71 HARV. L. REV. 593, 594 (1958); see RAz, supra note 116, at 37-45.

120 See $i d$. at 47 .

121 It does not necessarily follow that one may ignore morality in identifying the law. Morality may be relevant insofar as it is embodied in social facts that are criterial. A criterion for law might be that a rule becomes law only as a result of a 
This positivist account of law has the important corollary that the law has gaps. ${ }^{122}$ Whenever (according to relevant social facts) a rule does not exist for a particular situation, the law is undetermined. ${ }^{123}$ Determining the gaps may be difficult and controversial, and one may come to feel that the social facts do not, in this sense, speak for themselves.

\section{Dworkin's Criticisms}

Critics of positivism such as Ronald Dworkin challenge the positivist's claim that identifying the law is a matter of looking at social facts and not a matter of producing justificatory arguments. ${ }^{124}$ Dworkin suggests that judges go through a different and more complex process of deliberation when they try to identify the law, one in which social facts and justificatory arguments are inextricably bound. ${ }^{125}$ In rejecting positivism, Dworkin argues that justificatory arguments play an essential role in the process of identifying law. ${ }^{126}$ Dworkin's critique anticipates some of the insights of law as a deliberative practice, while falling short, as we shall see, in other respects.

\section{B. The Limitations of Positivism}

Viewing law as a deliberative practice shows how problematic the central claims of positivism are. It requires us to extend and modify the positivist understanding of the identification of law. We must look critically at the positivist's claims about the criteria of validity (the sources thesis), the nature and role of justificatory

popular referendum, and the referendum might ask voters for approval or disapproval on moral grounds. In this example the positivist's claim stands. The judge-or other player-who is trying to identify the law appeals to social fact and has no occasion to offer justificatory arguments of her own. See id. at 38-39 (explaining that the "social facts by which we identify the law" may "endow [the law] with moral merit," but the law itself does not "of necessity conform to . . moral values").

${ }^{122}$ See id. at 73 (stating that "the source thesis makes [gaps] unavoidable since it makes law dependent on human action with its attendant indeterminacies").

123 See id. at 70.

124 Dworkin puts to one side whether, from the standpoint of the citizen, identifying and citing the requirements of law are indeed (as Raz maintains) a matter of social fact, as they appear to be. For example, determining the taxability of one's capital gains involves consulting rules that have a particular pedigree, rules that came into effect through the actions of authorized individuals. Being able to point to the "social fact" that these actions occurred is sufficient to identify the law.

125 See DWORKIN, supra note 36, at 238-66; DWORKIN, supra note 47, at 81-130.

126 See infra part III.C.1. 
arguments in law, the appropriate role of theorists and participants (the game metaphor), and the existence of legal gaps.

\section{Criteria of Validity}

Notwithstanding the positivist suggestion that clear criteria (social facts) identify valid legal rules, the practice of judicial decision-making exists because rules of law are continually and characteristically in dispute. Judges who disagree offer significantly different conceptions of the rules. In considering hard cases, appellate judges necessarily ask whether fellow judges see the law as they do, take differences of opinion and result seriously, and argue about whether and how the law has changed. For positivists, a second-order set of game-like rules applies to judges' deliberations. These rules direct the judge to use certain sources of law. ${ }^{127}$ Having identified the law, the judge may decide that the case falls in the gaps of the law ${ }^{128}$ and may, in a discretionary way, use considerations outside the law to make new law. ${ }^{129}$

Critics such as Dworkin offer a different picture of judging. They imply that a judge's understanding and use of such game-like rules is necessarily colored ab initio by preconceptions about the interests at issue in the particular case, their weight and importance, and the relation of the case to other situations and contexts. Each judge makes decisions about relevance in the light of a justificatory

${ }^{127}$ Hart explains:

The simplest form of remedy for the uncertainty of the regime of primary rules is the introduction of what we shall call a 'rule of recognition'. This will specify some feature or features possession of which by a suggested rule is taken as a conclusive affirmative indication that it is a rule of the group to be supported by the social pressure it exerts.

HART, supra note 21, at 92 (emphasis omitted).

${ }^{128}$ Raz, argues:

Questions of intention and meaning may have no answer.... Where the facts which are legal reasons are indeterminate, through vagueness, open texture, or some other factors, certain legal statements are neither true nor false .... It is worth noting that this kind of legal gap is not the law's peculiarity. They are totally dependent on and derive from gaps in statements of an ordinary and not a particularly legal kind such as statements about intentions and language. It is the indeterminacy of ordinary everyday facts which generates legal gaps.

RAZ, supra note 116, at 72-73 (footnote omitted).

129 See HART, supra note 21, at 132 (stating that the "open texture of law means that there are, indeed, areas of conduct where much must be left to be developed by courts or officials striking a balance, in the light of circumstances, between competing interests which vary in weight from case to case"). 
argument identifying the interests that matter. ${ }^{130}$

Dworkin's view of judging is compatible with seeing judicial decisionmaking as a deliberative practice. Without a framework derived from her own way of interpreting experience and giving value, the judge cannot know where to begin. The process of identifying the law cannot be reduced to rules because it cannot be separated from the judge's distinctive way of conceiving justificatory arguments and using them to work toward a decision. What the judge sees as determinate and indeterminate in the law is colored by her understanding of the justificatory arguments that the law encompasses. ${ }^{131}$

Disagreement among judges therefore extends both to the criteria by which they treat the available body of precedent (decisions and arguments) and to their conception of the goals and interests at issue. Although they may agree on the importance of order and fairness, hard problems are not solved at this level of generality. If they were, judges would not disagree with each other.

The argument against shared second-order rules for judging is that the standards of decision-making are inherently disputable. Judges lack shared bases for determining how the ingredients of decision yielded up by the sources of law are to be weighed and fitted together. As a result, justificatory arguments are needed at every stage to support these controversial determinations. No judge sees herself, as some positivist descriptions suggest, as engaged in a bifurcated task of first applying the first-order rules when possible and then looking to resources outside the rules when application of the first-order rules is not possible. At any level but the most abstract, judges may disagree about the point of their activity and the goals to be achieved.

\section{The Meaning of Legal Justification}

Do positivists misdescribe the kinds of justification found in judicial reasoning? Their account of law implies that there are three kinds of justificatory moves in legal discourse. One kind is a demonstration that a particular rule is a first-order rule of the system performed by displaying the rule's pedigree. ${ }^{132}$ The

${ }^{130}$ See DwORKIN, supra note 36, at 238-66; DWORKIN, supra note 47, at 81-130.

131 Of course, none of this is fixed. The judge's confrontation with the arguments of others or with new circumstances for applying the law-new cases-may lead her to reconceive aspects of her understanding of the law and look at a point of relevant law in a new way.

132 This notion of justification follows directly from the positivist account of legal 
second kind is an account of why (or why not) a case falls within the scope of the relevant first-order rule. ${ }^{133}$ If the case falls outside, a third kind of justification is appropriate: an argument for the extension of the law in terms of the purpose that is thus achieved. ${ }^{134}$

Positivists see these three kinds of justifications as offering an exhaustive analysis of justification as it arises in different aspects of the process of decision-making. In the actual use of justificatory strategies by judges, however, justification cannot be analyzed in this way. Questions about the scope of relevant law and about the purposes to be achieved by particular results are typically not distinguishable in judicial opinions. ${ }^{135}$ Identifying the law itself necessarily involves justificatory arguments.

Such a melding of the question of identifying the law with the question of justifying particular results is not an aberration from the ordinary context of decision-making; it is the ordinary context. Participating in a deliberative practice, a judge has a stake in a

validity. See HART, supra note 21, at 97-107.

${ }^{133}$ This notion of justification falls within the positivist conception of open texture. See id. at 124-32 (explaining that rules will at some point prove indeterminate, possessing what is called an open texture).

${ }^{134}$ The role of consequentialist arguments and other kinds of "second-order" justifications are discussed at length by writers in the positivist tradition. See, e.g., MACCORMICK, supra note 21, at 100-51.

${ }^{195}$ In Bowers v. Hardwick, Justice White, speaking for the Court, wrote:

[W] think it evident that none of the rights announced in [such cases as

Pierce, Skinner, Griswold, and Roe] bears any resemblance to the claimed constitutional right of homosexuals to engage in acts of sodomy that is asserted in this case. ... [A]ny claim that these cases nevertheless stand for the proposition that any kind of private sexual conduct between consenting adults is constitutionally insulated from state proscription is unsupportable.

Bowers v. Hardwick, 478 U.S. 186, 190-91 (1986) (citations omitted). Was White identifying the law, that is the scope of the right of privacy, or was he justifying a limitation upon it by finding a conceptual difference, embedded in how he and some others view human experience, between some private acts and others? Clearly he was doing both, and the distinction between the two-identification and justification-is idle.

In Rochin v. California, the Court held it to be a violation of due process for officers to compel evidence from a defendant by forcing him to yield up the contents of his stomach. The Court said, "This is conduct that shocks the conscience. ... [These] are methods too close to the rack and the screw to permit of constitutional differentiation." Rochin v. California, 342 U.S. 165, 172 (1952) (Frankfurter, J.). Did this constitute identification of the scope of the law, or did it offer a justification by explicit reference to moral limits and moral similarities? Clearly it did both. The point is perfectly general: in virtually any opinion, the processes of identifying the law and of offering up justifications for a decision are inseparable. 
particular way of interpreting experience and therefore in a particular way of putting together the elements of a legal system. Judges mutually understand the various styles and assumptions encompassed within their shared deliberative practice, and such understanding is crucial to the ongoing practice, but it does not generally or necessarily move them toward convergence.

\section{Participants and Theorists}

Positivists ascribe different roles to participants (judges) and theorists (observers). Participants make justificatory moves in the course of making decisions while theorists analyze the formal structure of rule-governed activities. ${ }^{136}$ This means that positivists separate the analytic and the normative aspects of legal theory. ${ }^{137}$ What law is and what law ought to be are separate issues. The job of the judge is bifurcated between justifying decisions within the scope of existing law (the first and second kinds of justification) and justifying new or gap-filling law by extralegal considerations (the third kind of justification). The theorist's job is bifurcated between describing the practice of legal reasoning and criticizing its substance.

136 This distinction is implicit in the positivist's separation of law as it is and law as it ought to be. H.L.A. Hart explains:

[I]t is . . . important to distinguish as belonging to the philosophy of law certain groups of questions which remain to be answered even when a high degree of competence or mastery of particular legal systems [by] ... empirical and dogmatic studies ... has been gained. Three such groups may be distinguished: problems of definition and analysis, problems of legal reasoning, and problems of the criticism of law.

H.L.A. HART, ESSAYS IN JURISPRUDENCE AND PHILOSOPHY 88-89 (1983).

For critics of positivism, problems of definition and analysis are not altogether separable from problems of the criticism of law. "It is his neglect to analyze the demands of a morality of order that leads [Hart] throughout his essay to treat law as a datum projecting itself into human experience and not as an object of human striving." Lon L. Fuller, Positivism and Fidelity to Law-A Reply to Professor Hart, 71 HARV. L. REV. 630, 646 (1958). The point of stressing the diversity of justificatory strategies in deliberative practices is that each judge conceives of law as "an object of human striving" in a different way, that such commitments affect theorists as well as judges, and that a full account of the definition and analysis of law will betray the theorist's own commitments.

${ }^{137}$ See HART, supra note 136, at 88-89. In The Concept of Law, Hart separates his consideration of analytic questions (chapters one through seven) from his consideration of questions of the criticism of law (chapters eight and nine). See HART, supra note 21. Compare RAZ, supra note 116 (discussing analytical questions) and JOSEPH RAZ, THE CONCEPT OF A LEGAL SYSTEM (1970) (analyzing legal systems) with JOSEPH RAZ, THE MORALITY OF FREEDOM (1986) (discussing moral criticism of law). Both Hart and Raz see these questions as falling into separable domains of jurisprudential inquiry. 
To see judicial decision-making as a deliberative practice is to see that such clear lines of demarcation are illusory. Just as a judge will necessarily make justificatory arguments in the course of identifying the law and will have a particular stake in a way of ordering the results, a theorist will look at the institutions of law in terms of the justificatory arguments that are relevant to its existence. ${ }^{138}$ The positivist is correct that part of the theoretical task is to understand what law is by identifying law with a particular institutional structure. Making sense of that institutional structure, however, requires a choice among various explanatory datapolitical, social, economic, psychological, and so on. The choice that a particular theorist makes will represent that theorist's own way of making sense of experience. A theorist will also have to address a range of questions about the functional, dysfunctional, or nonfunctional character of legal decisions and official acts. In so doing, she will have to confront the availability or absence of particular justificatory arguments for what the legal system does.

Thus the tasks of judge and theorist, while hardly the same, are isomorphic in a way to which the game-based metaphor of insider/ outsider cannot do justice. It is unsatisfactory to imply, as positivism does, that a judge (insider) applies rules and on occasion creates new law while a theorist (outsider) describes the institutional structure generated by such rules. Both the judge and the theorist are participants in deliberative practices. They deliberate for different ends: the judge deliberates to decide cases, while the theorist deliberates to arrive at an adequate characterization of law. But when both judges and theorists disagree with their peers, their disagreements turn on differences with their peers in the way experience is understood, differences in preferred explanatory strategies. Thus, both judges and theorists have a stake in a personal way of understanding the place of law in the social order because each judge and each theorist is necessarily a partisan of some particular and controversial way of arriving at knowledge and certainty.

138 Thus, one theorist may identify the institutions of law with order and discipline, another with the realization of justice, and yet another with the coordination of wants and aspirations. Moreover, the theorist's elaboration of the demands of order or justice or want-satisfaction will depend in turn on that theorist's way of understanding human psychology, history, politics, morality, etc. 


\section{Dissolving the Dichotomies of Positivism}

The main pillars of positivism are undermined by these three criticisms of positivist approaches to identifying the law, to the nature of justification, and to the relation of theory and practice. The claim that law can be identified by recourse to formal sources without the use of justificatory arguments fails. From the standpoint of law as a deliberative practice, every attempt to link disparate elements-statutes, case holdings, constitutional clauses-is a way of understanding and creating order. The shared practice is defined by the collection of permissible and mutually recognizable ways of creating order. Each participant's way of creating order is in part idiosyncratic and each is called upon to justify her way of doing so at every stage.

\section{a. Existing Law and New Law}

Positivism's conceptual distinction between cases in which a judge applies law at its core and cases in which a judge must reach outside the law to make new law ${ }^{139}$ is problematic. In practice, the claim that a judge is making new law is generally reserved as a criticism for some results with which one disagrees. Judges themselves do not use this bifurcation to describe their own decisions, but rather characterize all their own decisions as interpreting and extending existing law. At the same time, they often accuse those with whom they disagree of making new law and therefore of being self-evidently in error. ${ }^{140}$

The implication is not that judges always deploy "old law" but that the distinction between old and new law, and the dilemmas it spawns, must be dissolved. Each judge identifies law and legal reasoning with certain analytic strategies and moral/social/political principles, and her decisions use those strategies and principles to address new issues. The decisions are old insofar as the judge does

139 See HART, supra note 21, at 124-32 (describing legal rules' open texture). See also supra note 132.

140 Even Roe $v$. Wade, a case that seems to many commentators a clear instance of judicial lawmaking, is presented as an application of existing law. "This right of privacy, whether it be founded in the Fourteenth Amendment's concept of personal liberty . . . as we feel it is, or . . . in the Ninth Amendment . . . is broad enough to encompass a woman's decision whether or not to terminate her pregnancy." Roe v. Wade, 410 U.S. 113, 153 (1973) (Blackmun, J.). And dissenters predictably see and accuse the majority of making new law: "I have difficulty in concluding . . . that the right of 'privacy' is involved in this case." Id. at 172 (Rehnquist, J., dissenting). 
not reinvent strategies and principles with each case, and new insofar as particular issues have not been met before.

Seeing law as a deliberative practice explains why "new law" is an epithet of criticism. Each individual judge, as we have seen, has a favored account of the methods and goals of the enterprise; accordingly, one will try to reconstruct the social order that seemed to be set in place by the founders, another will look to a consensus about goals and rights within the political and cultural community as it has evolved, and so on. Moreover, a particular judge will necessarily have to vary her methods to meet the demands of different kinds of cases. In a consistent and principled way, she may decide some cases by reference to economic considerations, others by reference to historical intent, and still others by looking at fairness, freedom, and other moral values. ${ }^{141}$

Every judge will therefore find some cases that require the use of resources that are not generally seen by others as part of the law. Some judges will use controversial resources more readily than others. ${ }^{142}$ What seems to one judge a decision within agreed upon bounds of the law will seem to another a creative extension of the law.

The alternatives confronted by positivists and their critics are therefore a misleading way of posing the issue. Positivists suppose that one can sort cases into applications of pre-existing ("old") law and instances of law creation. Their critics, like Dworkin, argue that all cases are applications of pre-existing law. ${ }^{143}$ Both claims fail.

141 For example, she may use economic criteria in antitrust cases, copyright and trademark cases; she may be guided by historical considerations in deciding cases about the balance of powers among the three branches of government; and she may refer to fairness and freedom in deciding cases under the First, Fourth, and Fifth Amendments. She will be able to explain why she finds economic criteria relevant to one sort of case, historical concerns to another, and fairness and freedom to others. Moreover, what distinguishes her justificatory strategies is not only how she categorizes various cases but also the particular economic, historical, and moral convictions that she regards as true and relevant.

142 Justice William Douglas was, throughout his career, seen, praised, and pilloried for being an innovator of this kind. See generally VERN COUNTRYMAN, THE JUDICIAL. RECORD OF JUSTICE WILLIAM O. DOUGLAS (1974) (discussing Justice Douglas's career on the United States Supreme Court).

143 See DwORKIN, stpra note 50, at 119-45. Dworkin states that

[t]he question ... of whether there are no-right-answer cases in a particular jurisdiction, [that is, cases in which existing law does not anticipate a right answer]-and whether such cases are rare or numerous-is not an ordinary empirical question. I believe that such cases, if they exist at all, must be extremely rare in the United States and Great Britain. . . .

The argument that I am wrong must . . . be a philosophical argument. 
The process for arriving at and justifying decisions does not warrant either description, nor does it afford a perspective from which either description can be made.

Rather than applying existing law or making new law, judges draw on their individual strategies within the mutually familiar dimensions of the practice to solve a problem and create intellectual order. Some cases will be similar to existing precedents and give rise to little surprise or controversy. Other cases will seem more creative and disputable. The latter may continue to be described by observers as "making" law rather than "applying" it, but such a dichotomy will rightly be treated as naive and oversimple by judges themselves.

\section{b. Law and Gaps}

The same oversimplification is involved in the question of whether law has gaps, a question which also dissolves under scrutiny. On one hand, some cases involve significantly new questions and give rise to controversy. On the other, the range of strategies of decision available within the deliberative practice are almost always predictable, as is the range of the solutions they would yield. Of course, particular results in close binary cases ${ }^{144}$ cannot be anticipated. But the family of relevant arguments for each side of the binary question can and will be anticipated.

\section{c. Law as It Is and Law as It Ought to Be}

A third positivist claim is that theorists must keep in mind a clear distinction between what law is and what it ought to be. In particular, positivists maintain that justificatory arguments are used in determining what law ought to be but not in determining what it is.

If justificatory arguments in fact play an essential part in both

It must challenge my assumption that in a complex and comprehensive legal system it is antecedently unlikely that two theories will differ sufficiently to demand difficult answers in some case and yet provide equally good fit with the relevant legal materials.

Id. at 144-45.

${ }^{144}$ All cases are binary, of course, insofar as the claim of the plaintiff may either be upheld or denied. My suggestion is that the "gappiness" of a given case dissolves into the answers to such questions as: What decision is consistent with the justificatory argument (within the law) that I (as judge) find most compelling and relevant? How similar is this case to existing precedents? How much diversity can 
processes, then the distinction does not hold. Moreover, the distinction between settled law and new law is itself problematic. What one judge considers new law another judge will consider an application of established principles. It is thus simplistic to try to sort decisions into categories of those that reiterate settled law and those that announce what the law ought to be.

The distinction between what the law is and what it ought to be can, however, be translated into two functional distinctions. First, any judge would concede that some cases require creative extension of the law. Judges know that at some point what is generally regarded as settled law runs out. What does not run out is the capacity of each point of view within the practice to generate strategies to address unsettled questions. The distinction between what the law is and what it is becoming, according to the judge's way of viewing the law's justificatory strategies, remains real.

Second, every judge must recognize cases in which constraints of law require a result different from what she would choose had she been free to adjudicate on a clean slate. In that sense as well, therefore, what law is is one thing, what it ought to be is another. ${ }^{145}$

\section{Dworkin's Criticisms and Deliberative Practices}

Ronald Dworkin's response to legal positivism dovetails in some respects with the view of law as a deliberative practice. He claims that justificatory arguments are part of the process of identifying the law, that the law does not have gaps, and that no sharp distinction can be drawn between law as it is and law as it ought to be. ${ }^{146}$ His account is, however, deficient in significant ways.

I expect among my colleagues (both in decision and justificatory strategy) in deciding this case? How much controversy will any decision of this case generate?

145 Throughout this article, I assume that judges use justificatory strategies that they themselves find compelling and that reflect their own stake in a way of thinking, in a way of making sense of experience. I assume, in other words, that judges judge in good faith. For a general discussion of this assumption, see STEVEN J. BURTON, JUDGING IN GOOD FATTH (1992).

146 See DWORKIN, supra note 36, at 225-75; DWORKIN, supra note 47, at 81-149. 


\section{The Self-Understanding of Judges}

The judge as participant in a deliberative practice is in tension between (1) having a stake in both a particular result and a particular way of defending that result and (2) being aware that the practice embraces other justificatory strategies, some of which yield contrary results. ${ }^{147}$ The judge's attitude toward her persuasive powers is also bifurcated. She aspires in the short term to bring other judges around to her way of reasoning and to address the larger audience that reads and criticizes judicial opinions. At the same time, she is aware that she has no transcendental argument for the superiority of her way of proceeding or for a neutral standard by which ways of thinking are to be measured or ranked. She knows that in the long run the diversity of views and strategies that is characteristic of the practice will almost certainly persist.

Dworkin seems sanguine about resolving these tensions. By his account, a judge sees it as her task to offer the most comprehensive and defensible account of the rules and principles of the evolving legal system. ${ }^{148}$ The values and rights reflected in her account yield a complete legal system insofar as they anticipate a single "best" resolution of all hard cases. ${ }^{149}$ Even if a judge cannot convince her colleagues to adopt the same reconstruction of the legal system, she will remain convinced that all other strategies which yield different results are inferior. This conviction will be an essential part of her position. What is wrong with this characterization?

\section{a. The Bases of Disagreement}

Dworkin's account distorts the main obstacle to agreement by misconceiving the character of judges' disagreement. The problem is not only that judges accord different weight to different principles, as Dworkin claims, but that they have different ways of

147 Of course, other judges may arrive at the same decision by different means.

${ }^{148}$ See Dworkin, NATURAL, supra note 54, at 169-73. Dworkin analogizes the interpretation of law to the interpretation of novels:

We [must distinguish] two dimensions of a successful interpretation. An interpretation must "fit" the data it interprets, in order not to show the novel as sloppy or incoherent, and it must also show that data in its best light, as serving as well as can be some proper ambition of novels.

Id. at 170 .

${ }^{149}$ See DwORRIN, supra note 50, at 143-45 (arguing that rarely, if ever, do judges believe that there is no correct answer). 
ordering categories of evidence. Thus, one judge will give argumentative finality to social and moral arguments of a utilitarian character. Yet this judge can also recognize that the deliberative practice includes some judges who justify results by appeal to the structure of original intentions embodied in the Constitution and statutes and still others who argue by appeal to economic efficiency.

It is one thing to have a stake in a particular way of understanding evidence and constructing arguments. It is another thing to have a stake in a particular social agenda with its attendant values and goals. For Dworkin, judges differ essentially in the second way: they reconstruct in different ways the evolved system of social values that comprises the constitutional system. ${ }^{150}$ Each judge is in a position to see his reconstruction as superior and as broad enough to encompass the entire practice. Each judge clearly has a vested interest in maintaining this perception.

\section{b. Understanding Other Judges}

The picture of law as a deliberative practice, however, tells a different story. If judges also differ in the ways in which they understand evidence and construct arguments, and if they are aware of these differences, then they see their peers as not merely telling inferior stories but as telling characteristically different kinds of stories-political stories, economic stories, psychological stories, and historical stories. This awareness may cause them to hesitate before ranking such differences as superior or inferior and may lead them to a better understanding of why others resist accepting their stories. ${ }^{151}$

For Dworkin, all judges are in one sense playing by the same rules or strategies since they are deploying the two dimensions of legal analysis: fit and justifiability. ${ }^{152}$ Judges in a deliberative practice, however, play by different rules and have different modes of arguing, reasoning, and thinking, a fact they understand, anticipate, and respect. This acknowledgement creates a tension between their stakes in their individual strategies and in the

${ }^{150}$ See DWORRIN, supra note 36, at 257-58 (concluding that when a judge is faced with a hard case he is forced "to develop his conception of law and his political morality together in a mutually supporting way.").

151 I am not arguing, however, that this recognition will undercut or diminish one's own stake in one's way of proceeding, one's justificatory and analytical strategies.

${ }^{152}$ See supra note 150. 
multiform practice itself. The first stake is a stake the judge has by virtue of his position as a participant and a decision-maker. The second stake reflects the judge's awareness of the nature of the practice and his participation in it. The voice of the judge simultaneously expresses both stakes. ${ }^{153}$

\section{c. The "Best" Interpretation of the Law}

Dworkin says that the task of the judge is to produce the "best" interpretation of the law. ${ }^{154}$ What becomes of that claim when law is seen as a deliberative practice? A judge is most likely to defend her interpretation as the best to those who share at least some elements of his own strategy. Two judges similarly disposed to reconstruct original intent may still join issue with divergent views of original intent. On the other hand, two judges with different strategies may have to acknowledge the absence of any measure between them. Certainly each judge will continue to think of his own strategy and judgment as "best" in some sense. But the claim will be enlightened by awareness of this dual challenge, in terms of result and in strategy of thinking.

This distinction between Dworkin's position and mine is not a distinction between objective and subjective conceptions of what is "best." Any judicial opinion is an objective judgment insofar as it is a claim made from the perspective of a particular way of ordering evidence and justified by arguments marshalled from that perspective. All judicial opinions share these traits, and in this sense all arguments are therefore objective. ${ }^{155}$ Decisions are not any less objective because they involve strategies of justification that are to some extent individualized.

153 The coexistence of these two stakes should not be reduced simply to the degree of modesty of the judge or the degree of respect she has for her colleagues. It is a conceptual matter that the two stakes coexist, regardless of whether the judge is actively thinking about them or not; it is not an empirical matter dependent on the judge's attitude or personality.

${ }^{154}$ See DwORKIN, supra note 36, at 239 (comparing judicial decisionmaking to literary story writing).

${ }^{155}$ Both Dworkin and Fish tend to equate the requirement of objectivity with transcendental justification, which is itself impossible to achieve. See DwORKIN, supra note 36 , at 85-86; FISH, NATURALLY, supra note 19, at 87-88, 436-37. Dworkin identifies the call for objectivity with the call for a definitive argument refuting external skepticism. DWORKIN, supra note 36, at 85-86 (stating that the "only skepticism worth anything is skepticism of the internal kind"). 


\section{The Completeness of Law}

Dworkin takes a strong stand on the completeness of law. Along with some other proponents of legal naturalism, he shares the assumption that the principles and values of the legal system anticipate decisions for all cases. Therefore, no decision involves making new law. As reconstructed by each judge, the values and ideals embodied in the law color and shape each new hard case so that it is a reading of what is already implicit.

From the standpoint of law as a deliberative practice, this claim must be sharply qualified. One may agree with Dworkin that every hard case summons up an array of interests and values that have surfaced in other cases and on which any judge has probably taken a stand. Only in this sense is a place in the legal system already prepared for any new judicial decision.

The claim that the decision in every hard case is already part of the law and that judges never create new law is nonetheless counterintuitive. However, the positivists' claim that judges sometimes make new law is also counterintuitive, and both claims rest on oversimplification. Every judge sees some cases as requiring her to extend legal arguments in ways they have not been extended before. ${ }^{156}$ At the same time, she does not think of herself as sometimes applying preexisting law and sometimes making new law. Rather, she sees her responses to some cases as creative and innovative, and she expects them to be surprising and controversial. The static metaphor of inside/outside yields to the dynamic metaphor of growth and extended reach.

The idea of closure and completeness is inapposite to the extent that judges are aware that legal reasoning involves not just one strategy of reasoning. Every decision is likely to invoke coexisting yet competing strategies, with each strategy yielding its own innovations and each capable of providing for growth and development of the law in a different way. ${ }^{157}$ Again, the claim that the law

${ }^{156}$ See supra text accompanying notes $139-45$.

157 Again, one could cite examples endlessly. In DeShaney v. Winnebago County Dep't of Social Servs., 489 U.S. 189 (1988), the Court refused to hold a state agency liable when the agency, having intervened in a child abuse situation, failed to take reasonable measures to protect the victim. Speaking for the majority, Chief Justice Rehnquist relied on the framers' intent in interpreting due process to exclude claims against the state when harm resulted from purely private action. See id. at 196-97 (stating that the purpose of the Due Process clause "was to protect the people from the State, not to ensure that the State protected them from each other"). In dissent, Justice Brennan examined the evolving duty of the state to protect individuals in 
anticipates particular results will seem vastly oversimplified to any judge who understands the law as a collection of different strategies and a perpetual contest among them.

\section{ANTIFoundationalism ANd PRAgmatism}

Viewing law as a deliberative practice allows us to transform the "old" jurisprudence by reinterpreting the claims of positivists and liberal/naturalist critics. This approach does so largely by questioning the scope and possibility of consensus and by emphasizing that the practice is made up of conflicting and irreconcilable points of view or strategies of decision. This way of summarizing the critique seems to assimilate the description of law as a deliberative practice with critical theory or antifoundationalism-the "new" jurisprudence. That would be wrong. Just as it faults the old jurisprudence for misconstruing agreement, that is, for misdescribing the limits of law and the role of justification, the view of law as a deliberative practice finds in critical theory a defective picture of the scope and nature of disagreement. ${ }^{158}$

\section{A. From Old to New Jurisprudence}

Antifoundationalists reject what Robert Gordon calls "evolutionary functionalism," 159 a general conception of law as evolving to realize social values by meeting human needs. ${ }^{160}$ Evolutionary

whose behalf it has begun to act. See id. at 207 (Brennan, J., dissenting) (recognizing "that 'the State's knowledge of [an] individual's predicament [and] its expressions of intent to help him' can amount to a 'limitation on his freedom to act on his own behalf.") (alteration in original) (citation omitted). Justice Blackmun stressed the general role of the state in preventing harm. See id. at 213 (Blackmun, J., dissenting) (calling for a "sympathetic" ruling). It is easy to imagine a more general use of the framers' intent criterion to limit claims against the state and overturn existing precedents in which, for example, public officials acting in what is arguably a private capacity have been held liable. On the other hand, expansive use of the notion of the state's obligation to prevent harm by private persons could lead to new kinds of tort claims against the state, and new obligations for state agencies. Another approach to this issue could be grounded on economic efficiency, specifically on an analysis of which party is best situated to prevent harm in such cases at least cost to the parties and to society.

158 Obviously, one might argue that the difference between my theory and critical legal theory, or for that matter between my theory and Dworkin's theory, is a matter of nuance and emphasis rather than a difference in kind. That determination, in turn, depends on whether one is impressed more by what the theories have in common or by what differentiates them. Such a determination rests in the hands of the reader.

${ }^{159}$ Gordon, supra note 3, at 68.

${ }^{160}$ Positivists and antifoundationalists both attack what I have called consensus 
functionalism comes in two guises. For consensus theorists, the law incorporates principles that represent such social values, principles that constantly require interpretation and extension. For positivists, law is a neutral tool that can either be used to realize social values or to subvert them. ${ }^{161}$

Antifoundational skeptics do not simply reserve normative questions about needs and social values; they subvert them. Positivists take no position on the truth of propositions linking law, need, and social values in practice; they commend the conceptual distinctiveness of law as it is and law as it ought to be without regard to whether law embodies social values founded on human needs. Antifoundationalists, however, do take a position on these propositions: they tend to regard the rhetoric of needs and shared values as camouflage for the use of power to create order and to give the veneer of justification without the substance. Like

theory, represented in contemporary debates most conspicuously by liberalism. Consensus theory maintains that law embodies shared social values and that the judge's job is to ferret out, interpret, and apply them. If this were all that consensus theory held, then positivists would have no cause for rejecting the view that identifying the law may involve recourse to shared values. Consensus theorists also maintain, however, that the process of identifying the law involves justificatory arguments for particular values-arguments showing both that the values are shared and that they explicate what is good. Consensus theory thus bridges what law is and what it ought to be and takes on a task that is simultaneously descriptive and normative. In this way consensus theory stands directly against a major tenet of positivism.

Liberals modify consensus theory by distinguishing public values, in particular freedom and equality, from personal values. The liberal argument is that by realizing public values, a legal system can remain neutral vis-a-vis personal values. The point is sometimes made more strongly: some liberal theorists claim that the public values of liberalism entail neutrality affecting private preferences. See, e.g., H.L.A. HART, LAW, LIBERTY, AND MORALITY 20 (1963) (noting that legal coercion of positive social morality "calls for justification as something prima facie objectionable, to be tolerated only for the sake of some countervailing good"); RAwLS, supra note 38, at 207-08 (noting that "from the perspective of the original position, there is no way of ascertaining the relative strength of various doctrines").

161 See Hart, supra note 119, at 615-21 (noting the problems posed by the historical example of Nazi Germany for positivist conceptions of law).

Defining law as order effected and sustained through authority, positivism holds that the substance of law, and $a$ fortiori any question of whether law serves human needs, is irrelevant to the identity of law. From the point of view of positivism, all three essential claims of consensus theory-that there are universal human needs, that such needs are the ground of social value, and that law expresses and realizes these values-are irrelevant to identifying law. The point of identifying and citing something as law is, in Raz's sophisticated version of positivism, a way of preempting justificatory moves and thus putting such normative claims about law in their separate, distinct, and important place. See supra text accompanying notes 124-26. 
positivists, they stress order and power; unlike positivists, they give the terms a critical import and tell a normative story. ${ }^{162}$

The new jurisprudence has two aspects: the skeptical and destabilizing arguments of the critical theory espoused by antifoundationalists, and the attempt to resolve these arguments in the social and philosophical theory of pragmatism. Each deserves independent examination.

\section{B. The Limits of Critical Theory}

\section{Myths of Value Pluralism}

Critical theory invites the use of the philosophical technique of dissolving questions by undermining their foundations. ${ }^{163}$ This technique is exemplified by our discussion of the positivist's question of whether and when judges properly step outside the law when deciding hard cases. ${ }^{164}$ No simple answer is satisfactory, and our analysis of the deliberative role of judges explains why this is so. ${ }^{165}$

The same kind of technique applies when the question is

162 Kelman states:

"Progressivism" may be undercut by the view that legal change simply reflects the dominance of whichever pernicious elite has grabbed a greater degree of control, the view that "modernization" is predominantly gloomy, destroys communal bonds, decent work, faith, and family, and/or that development has generally moved us from a society of independent, civicminded, and public-spirited citizens to a bunch of atomistic profit grabbers.

KELMAN, supra note 2, at 243. Similarly, Kathleen Lahey comments that

[o]ne of the greatest accomplishments of feminist legal scholarship has been to identify the ideological content of masculist legal theory, of legal reasoning, and indeed, of reasoning itself. To point out that this ideological content actually affects the real and lived lives of women is merely to demonstrate that ideas become real through ideology and that reality affects ideology....

... [W]omen who involve themselves with power processes live within the shadow of ideologies that are compatible with the acquisition and exercise of power. Thus it would not be surprising to find that women who are involved in power processes are themselves influenced by the very forces that they think they are combatting.

Kathleen A. Lahey, Reasonable Women and the Law, in AT THE BOUNDARIES OF LAW 3, 3-4 (Martha A. Fineman \& Nancy S. Thomadsen eds., 1991).

163 See WITTGENSTEIN, supra note 22, at 51 (stating that "the clarity that we are aiming at is indeed complete clarity. But this simply means that the philosophical problems should completely disappear.")

${ }^{164}$ See supra part III.

${ }^{165}$ See supra text accompanying notes $127-45$. 
whether or not different judges adhere to reconcilable value systems. Naturalist critics of positivism, notably Fiss and Dworkin, struggle to show that reconciliation of value systems is manifest, especially in the light of the liberal's distinction between public values and private values. ${ }^{166}$ Naturalists also claim to demonstrate that the public values fleshed out in the constitutional system of rights offer answers to hard legal questions. Answers thus are forthcoming so long as the Constitution is interpreted through the liberal principle that the legal system exists to provide equal concern and respect for all individuals ${ }^{167}$ and to position all persons equally in the struggle to achieve personal values. ${ }^{168}$ The liberal consensus theorist tries to have both harmony and diversity. Skeptical critics argue that one precludes the other. The price of harmony is coercion; the cost of diversity is strife.

In contemporary jurisprudence, critical legal theorists have the distinction of making this point both descriptively and normatively, and they combine description with normative conclusions in an innovative way. The descriptive element alone is long familiar: philosophers throughout history have claimed that persons have differing value convictions and that value systems are therefore irreconcilable. ${ }^{169}$ Even some of the most prominent liberal theorists, including John Ely, ${ }^{170}$ acquiesce in this notion.

In contrast, critical legal theorists such as Kennedy, ${ }^{171}$ Tushnet, ${ }^{172}$ and Gordon, ${ }^{173}$ give the claim a normative spin. Recall that consensus theorists refer to fundamental needs and interests,

166 See supra note 48 . Note that critics of positivism who argue that law and moral argument are indissolubly linked tend to be labeled (sometimes by themselves) "naturalists," although the link to natural law theory is attenuated at best. Natural law theory, properly so-called, stresses universal rules of social organization, while writers such as Dworkin and Fiss discuss the links between the legal and moral rules and beliefs of a particular society or community.

167 See DWORKIN, supra note 47 , at 180-83.

168 See RAWLS, supra note 38 , at 90-94.

169 See ThOMAS HoBbes, LEviATHAN 63 (Michael Oakeshott ed., Oxford 1946) (1651).

170 See ELY, supra note 29.

171 See Kennedy, supra note 9, at 213-17 (discussing the legitimizing nature of legal thinking and categorical schemes).

172 See TUSHNET, supra note 50, at 313 (concluding that proponents of the possibility of constitutional theory advocate the imposition of the values of a particular elite).

${ }^{173}$ See Gordon, supra note 3, at 100-09 (summarizing varieties of critical legal historiography and describing the relationship between constitutive legal rules and the Hobbesian state of war). 
such as the need for concern and respect. To reject the idea of fundamental needs and interests and describe the realm of value as one of competing political agendas is, for critical theorists, to conclude that law is used to make one or another political agenda dominant. This turns law into a manifestation of a "legitimating ideology,"174 a story about value that is one of many possible stories, no one of which has priority. Law is thus inherently subject to criticism for claiming legitimacy that it lacks.

Consensus theorists answer the "one value system or many" question by reconciling diversity within one system; skeptics claim there are many. But the question itself rests on a distinction between fact and value, a distinction with a long history in philosophy and in what passes for common sense. ${ }^{175}$ The theory is that since descriptive discourse and evaluative discourse (fact and value) are separate, any general agreement about facts (of science, history, geography, etc.) has no implications for agreement or disagreement about value. Whether there is one value system or many is independently determinable.

To the extent that the "one value system or many" question rests on the fact and value distinction, it should be dissolved rather than answered. To understand deliberative practices is to see that what we call facts and values are interconnected and inseparable in justificatory structures. The justification of what is generally called a value claim, such as the infringement of a plaintiff's right to privacy or of his civil right against discrimination, is a legal argument consisting of facts of various kinds-historical, psychological, sociological, and so on. The judge, in offering a justificatory argument, assumes that there is a logical relationship between the facts and the conclusion. Justification would otherwise be impossible. ${ }^{176}$

The question of whether judges (or persons generally) have reconcilable or irreconcilable value systems dissolves into the question of whether persons have different but reconcilable

174 Id. at 93 .

${ }^{175}$ See supra notes 90-95 and accompanying text (discussing the relationship between fact and value).

${ }_{176}$ Thus, one judge may derive from the fact that the intent of the founders was to limit the scope of governmental intervention the evaluative conclusion that the claimant has no legal right to have privacy claims vindicated. Another judge may derive from the fact that a given allocation of burdens would be economically inefficient the evaluative conclusion that the claimant must bear the burden of a particular economic arrangement. 
justificatory patterns, reconcilable ways of pooling their beliefs about human nature, society, and the world, and of drawing conclusions from those beliefs. Differences over capital punishment, affirmative action, the rights of criminal defendants, and abortion are not simply the products of different systems of value, unrelated to fact. They are the functions of differing understandings of human nature, human history, human malleability, original sin, and so on, endlessly. Whether we call some of these beliefs values and some facts is nominal and arbitrary. What matters is that we see them as competing ways of orienting oneself to experience.

Understanding of law as a deliberative practice suggests that participants will generally recognize agreement of three kinds. They will agree on broad generalities about need and social value. They will agree on formal procedures for debate and decision. And they will agree in the mutual recognition of relevant arguments. Through these understandings, participants will know the dimensions of the debate. But none of this agreement assures consensus, not because participants subscribe to different value systems but because they have different histories and therefore different strategies for knowing, reasoning, and justifying. The vital stake that each participant has in ways of thinking will tend to perpetuate such debate, but the fact that their ways of thinking incorporate active consideration and evaluation of others' ways of thinking moves them toward change and accommodation. The most legal theory can tell us is that all debate is carried out in tension between these tendencies. The normative lesson, such as it is, is to maximize empathic consideration of alternative ways of thinking. ${ }^{177}$

\section{Conceptual Frameworks}

Some critical legal theorists are fully aware that the irreconcilable differences they claim to find are not between value systems as such but between ways of thinking that link fact and value. They regard such ways of thinking as discrete conceptual frameworks or conceptual schemes. Feminist theorists in particular appreciate the relationship between fact and value and argue that gender bias infects ways of describing the world. ${ }^{178}$ They are not alone, as

177 To the extent that one kind of value transcends all other kinds, arguably the value of openness and empathy toward the ways of thinking (justificatory strategies) of others is such a value. This claim echoes John Stuart Mill's commendation of a marketplace of ideas. See JOHN STUART MILL, ON LIBERTY 18-21 (David Spitz ed., W.W. Norton \& Co. 1975) (1859).

178 See, e.g., MARTHA MINOW, MAKING ALl THE DIFFERENCE 219 (1990) (arguing 
Robert Gordon remarks, in "historiciz[ing] consciousness."179 Their point is simple and in many respects compatible with an understanding of deliberative practices.

For critical theory, the historical dimension is just one of many ways in which conceptual frameworks are said to be relativized. Different groups of persons are characterized by different ways of thinking and feeling, understanding and experiencing. The divisions among groups are both diachronic and synchronic. Kuhn's insight into conceptual revolutions tends to emphasize change over time, resulting in the replacement of one conceptual system by another. ${ }^{180}$ Theorists also try to show that different conceptual systems coexist, most obviously in different societies, but also within a given society. ${ }^{181}$

\section{a. Forms of Conceptual Relativity}

In emphasizing conceptual relativity, critical legal theory distinguishes between the ways of thinking of the empowered and the powerless, between individualists and communitarians, and between the morally self-concerned and altruists. They claim that these fissures run deep, "all the way down" in legal thinking. All law, in this view, is politics. ${ }^{182}$

that "relational insights [of feminist theory] show a mutual dependence between 'normal' and 'abnormal' people, and between male norms and women who do not fit them. . . The act of judgment depends on and simultaneously forges a relationship. What qualities that relationship should attain becomes the most important question of law, informed by feminist theory."); Caroline Whitbeck, A Different Reality: Feminist Ontology, in ANN GARRY \& MARILYN PEARSALL, WOMEN, KNOWLEDGE, AND REALITY 51,51 (1989) (stating that "[feminist] ontology has at its core a conception of the selfother relation that is significantly different from the self-other opposition that underlines so much of so-called 'western thought'. Dualistic ontologies based on the opposition of self and other generate two related views of the person and of ethics: the patriarchal view and that of individualism.").

179 Gordon, supra note 3, at 98.

${ }^{180}$ See Kuhn, supra note 45, at 144-59.

181 See CLIFFORD GEERTZ, LOCAL KNOWLEDGE 215-19 (1983) (arguing that localizing forces of time, place, and narrative must be seen as both constructing knowledge and regulating behavior).

182 According to Duncan Kennedy:

The fundamental contradiction-that relations with others are both necessary to and incompatible with our freedom-is not only intense. It is also pervasive. First, it is an aspect of our experience of every form of social life. ... Second, within law, as law is commonly defined, it is not only an aspect, but the very essence of every problem. There simply are no legal issues that do not involve directly the problem of the legitimate content of collective coercion, since there is by definition no legal problem until 
Similarly, most influential feminists argue that women represent an underexpressed or unexpressed "different voice" not only on moral, social, and political issues, but also on such issues as human nature, history, and psychology. ${ }^{183}$ Every field of scholarly activity has been touched by the notion that a feminist perspective is distinctive and relatively unheard. Radical feminists add an important gloss, asserting that the search for this distinctive voice is tainted by the fact that women have always lived in circumstances of domination and alienation. For these scholars, the essential problem is that women cannot know what their voice would say unless and until they are free. ${ }^{184}$ Theorists such as Catharine MacKinnon stress the need to create rather than to find women's conceptual systems. She and others admit and address the paradoxical implications of this claim for their own work. ${ }^{185}$

The burgeoning field of critical race and ethnic studies shares this picture of conceptual relativity and fragmentation. Writers such as Richard Delgado and Mari Matsuda broadcast the need for underrepresented voices of Hispanics, African Americans, native Americans, and Asian-Americans to be heard. ${ }^{186}$ Others question the authenticity of voices that are the products of domination.

A constant theme of these many forms of critical theory is the

someone has at least imagined that he might invoke the force of the state.

Kennedy, supra note 9, at 213. In a similar vein, Unger states that

[t]he implication of our attack upon formalism is to undermine the attempt to rescue doctrine through these several stratagems. It is to demonstrate that a doctrinal practice that puts its hope in the contrast of legal reasoning to ideology, philosophy, and political prophecy ends up as a collection of makeshift apologies.

UNGER, supra note 9, at 11 .

${ }^{183}$ See, e.g., West, supra note 2, at 84-85 (suggesting that women's gender-specific, different experience may lack historic and linguistic reality in a male-dominated culture). For the pioneering work on "different voice" theory, see CAROL GILLIGAN, IN A DIFFERENT VOICE (1982).

184 See Catharine A. MACKInNon, Feminism Unmodified 32-45 (1987).

185 Catharine A. MacKinnon, Feminism, Marxism, Method, and the State: An Agenda for Theory, 7 SIGNS 515, 542-43 (1982) (noting that "[w]omen's bondage, degradation, damage, complicity, and inferiority... will operate as barriers to consciousness rather than as a means of access to what women need to become conscious of in order to change").

${ }^{186}$ See Matsuda, supra note 2, at 358-62 (noting that the "normative intuitions of those on the bottom are often different from the intuitions of those on top"); see also Richard Delgado, The Ethereal Scholar: Does Critical Legal Studies Have What Minorities Want?, 22 HARV. C.R.-C.L. L. REV. 301, 303-07 (1987) (arguing that critical legal theory analysis does not take account of minority experience, fails to confront racism, and may increase vulnerability of minorities). 
relationship of fact and value. Underrepresented groups, it is said repeatedly, not only have different political agendas, but also have different ways of thinking, different ways of assembling the facts of history, anthropology, sociology, psychology, and economics, and different ways of deploying them as justificatory arguments. This concern for the multiplicity of justificatory strategies in all their complexity parallels the lessons derived from attention to deliberative practices.

\section{b. Intractable Questions}

Nonetheless, viewing law as a deliberative practice underscores the limits and ambiguities of conceptual relativity as expressed in feminism, critical legal studies, and race/ethnic theory. Is a conceptual system monolithic, so that the elements of a system belong to it uniquely? What is a basis for distinguishing one conceptual system from another? Is it possible for those with different conceptual systems to communicate? How? Can a conceptual system change? How? What determines whether an individual has or projects one conceptual system or another? ${ }^{187}$

These questions are basic, difficult, and long familiar. They antedate the recent forays of critical legal theorists, ${ }^{188}$ and the implications of failing to answer them seem severe. For example, do the conceptual systems of men and women, white and black persons, privileged and powerless persons differ altogether? If so, how is communication possible? If not, what are the differences and how profound and tenacious are they? If the legal system is wholly the creation and expression of the conceptual system of the powerful (of men, of white persons), what theoretical explanation can be given for the possibility of change? How is a person's conceptual system determined-merely by gender, or by race, or by social class? Is one presumed to have a particular voice merely because of one's gender or race? If not, what follows?

The fact that these questions seem intractable is a clue to the fact that, however much they betray important issues, they too are pseudo-questions, questions to be dissolved rather than answered.

${ }^{187}$ See DONALD DAVIDSON, On the Very Idea of a Conceptual Scheme, in INQUIRIES INTO TRUTH AND INTERPRETATION 182, 182-84 (1984).

${ }^{188}$ See generally the various essays collected in the following volumes: ACTION AND INTERPRETATION (Christopher Hookway \& Philip Pettit eds., 1978); OBJECTIVITY AND CULTURAL DIVERGENCE (S.C. Brown ed., 1984); RATIONALITY AND RELATIVISM, supta note 28. 
When we discuss deliberative practices, the necessary focus of attention is the individual, with her personal ways of assimilating experiences, making judgments, and offering justifications. Given the heterogeneous character of justification, it should be clear that the individual has many kinds of belief. Some are universal, others idiosyncratic; some are controversial, others not; some are essential to her modes of thinking, while others are ones she would easily abandon. ${ }^{189}$ All aspects of the individual's thinking are a function of her personal history and capacities. She may believe, for example, in the free market, in individual responsibility, in personal corrigibility, and in limited government. These beliefs will be rooted in her personal "take" on history, economics, psychology, and so on.

The facts that she is a woman, black, and relatively privileged in terms of wealth and education-if such is indeed the case-will be important in determining some of her beliefs, but largely irrelevant to other beliefs. Her personal history may create unique perspectives on some issues that often distinguish women's or blacks' points of view. ${ }^{190}$ None of this can be known apart from her individual history and no pigeon-holing of her in terms of ethnic group or gender will tell us what ways of thinking she has or "should have."191 Moreover, we underestimate the individual if we disregard her capacity to recognize, anticipate, and respond to the alternative ways of thinking of others-her capacity to see herself as a participant in a diverse and complex deliberative practice.

\section{c. Abandoning Conceptual Relativity}

These objections play havoc with talk about conceptual systems. The examination of deliberative practices explains how dialogue and change occur, but it implies that it is nonsense to try to distinguish one monolithic conceptual system from another, to say that one ethnic group or gender group has an integrated and distinguishable way of thinking, or to make insoluble the problem of bridging

${ }^{189}$ See supra text accompanying notes 25-28.

190 See RALPH ELLISON, SHADOW AND ACT xix-xxiii (1972) (asserting the importance of black authors honestly and accurately depicting their attitudes and values as they exist, and not as others have conceived these attitudes and values for them.)

191 This point was illustrated during the Senate hearings that led to the confirmation of Clarence Thomas to the United States Supreme Court. Aspects of the confirmation process evinced race-based expectations of various parties. 
conceptual schemes. ${ }^{192}$

Attending to deliberative practices accomplishes these tasks in two ways. It focuses attention on the heterogeneity of belief and justification as opposed to the homogenizing language of conceptual systems. Thus, it shows that each aspect of an individual's way of thinking aligns her with some individuals and separates her from others. Each aspect-each set of beliefs and mode of justificationplaces one in a different community of like thinkers. In addition, attending to deliberative practices raises doubts about transcending practices in such a way that one can refer to them as self-contained, transcendable wholes, conceptual systems.

This does not mean that radicals should be less radical. It does mean, however, that radicals should frame their arguments by drawing justifications from within a shared deliberative practice. They misrepresent their aims and means when they insist on replacing conceptual schemes rather than challenging individual beliefs and justificatory strategies within the practice of judging.

\section{Semantic Relativity}

To summarize, the first subversive move of antifoundationalists is to assert that value relativity is irreducible. We saw that what is correct about this assertion is best captured by talking instead about the relativity of justificatory patterns or strategies-because value claims are underpinned by reasons, and one's reasons are determined by one's factual beliefs. ${ }^{193}$ The second subversive move links facts and values in asserting conceptual relativity. The insights achieved by this move are betrayed by the unsupported implication that one can distinguish discrete conceptual schemes and by the pseudo-dilemmas to which this implication gives rise.

A third and final subversive move is influenced by hermeneutic theory and inspired by writers on linguistic deconstruction. ${ }^{194}$ It

192 None of these observations is meant to prejudge when persons with different ways of thinking are or are not able to understand each other or when they will indeed reason at cross-purposes. They merely imply that the difference is to be sought in individual patterns of belief, reasoning, and justification rather than in gender- or race-based conceptual frameworks.

${ }^{193}$ See supra notes $189-91$ and accompanying text.

194 For provocative and influential writings on this topic, see generally JONATHAN D. CULIER, ON DECONSTRUCTION: THEORY AND CRITICISM AFTER STRUCTURALISM 712 (1982) (providing an overview of the writings on critical theory in the 1970s); JACQUES DERRIDA, WRITING AND DIFFERENCE xiv (Alan Bass trans., 1978) (1967) (setting forth a deconstructive account of reading texts); JEAN-FRANÇOIS LYOTARD, 
is an attack on the claim, implicit in positivistic theories of law and formalist theories of language, that words have determinate meaning. ${ }^{195}$ Although there are many sophisticated variations of hermeneutic and deconstructive procedures, they share the idea that the meaning of a text (utterance) is at least partly indeterminate and that therefore meaning varies from one reader to another.

Hermeneutics proceeds from a compelling main insight that one's way of understanding, whether the object be a text or other experience, is irreducibly affected by one's history. ${ }^{196}$ One can become self-conscious of these determinants, and thus alter one's ways of thinking, but one cannot cancel out the personal and idiosyncratic character of thinking. ${ }^{197}$ One application of the hermeneutic insight is that one can never think as the Founders did, even if one empathetically and perceptively takes account of historical change over two centuries and tries exhaustively to dispel naive assumptions about the Founders. ${ }^{198}$

The main hermeneutic argument can be used in two ways. One

THE POSTMODERN CONDITION: A REPORT ON KNOWLEDGE 3 (Geoff Bennington \& Brian Massumi trans., 1984) (1979) (offering a deconstructive analysis of the criteria for knowledge).

195 H.L.A. Hart reflects at length on the "open texture" of law which makes it impossible for judges to carry out a purely deductive or "mechanical" mode of decision-making. See HART, supra note 21, at 124-32. Thus, Hart distinguishes between the core and the penumbra of a rule, the latter being the area of application wherein judges may use discretion. This distinction does not go far enough because it suggests that although every rule has a core and a penumbra, the character of the core and the scope of the penumbra are matters fixed by language. This is not necessarily so. Judges and others may disagree about the core. A more satisfactory metaphor for the common or shared element of rules (or words) that make them generally intelligible is Wittgenstein's metaphor of family resemblances, whereby what one speaker regards as core-and-penumbra has some elements in common with what a second speaker regards as the relevant core-and-penumbra, etc. See WITTGENSTEIN, supra note 22 , at 32 .

196 See generally HaNs-Georg Gadamer, PhILosophical HeRMENEUTics 8-9 (David E. Linge trans. \& ed., 1977) (arguing that "there can be no doubt that the great horizon of the past, out of which our culture and our present live, influences us in everything we want, hope for, or fear in the future"); ROY J. HOWARD, THREE FACES OF HERMENEUTICS 16-17 (1982) (noting how hermeneutics differs from Kantian conceptions of reality); HERMENEUTICS: QUESTIONS AND PROSPECTS 4 (Gary Shapiro \& Alan Sica eds., 1984) (introducing a collection of essays on hermeneutics, and describing hermeneutics as "a type of philosophical activity or praxis, the effort to understand what is distant in time and culture . . . or obscured by ideology or false consciousness.").

197 See David C. Hoy, Interpreting the Law: Hermeneutical and Poststructuralist Perspectives, 58 S. CAL. L. REv. 135, 146-47 (1985) (suggesting that judges' viewpoints are necessarily conditioned by history and individual experience).

198 See id. at 150-52, 154-55. 
way is atomistic and skeptical and stresses the provisional character of discourse. It asks whether we can ever trust that meaning is communicated. At its logical extreme, this approach counterintuitively denies the possibility of communication and any kind of shared belief altogether. ${ }^{199}$

The second approach is more moderate and is favored by traditional hermeneutic theorists. David Hoy, for example, finds in Hans-Georg Gadamer the following view:

[T] he context itself conditions the reader's grasp of the text, not the other way around. Furthermore, the context is historical in that it changes over time with changes in the conditions influencing various readings. This insistence on historical variation in interpretation is not in the least subjectivistic or voluntaristic. On the contrary, the position entails that the reader is not completely free to decide the meaning of the text. The text is already determinate enough, for instance, to narrow the range of possible contexts. ${ }^{200}$

This more compelling and persuasive hermeneutic approach addresses not the impossibility of communication but its difficulties and constraints. It emphasizes equally what draws us together and what is idiosyncratic in strategies of understanding. This is, of course, a way of concerning oneself with the structure of deliberative practices. In contrast to Tushnet and Gadamer, one who looks to deliberative practices emphasizes both diachronic and synchronic variations in ways of understanding experience. Historical change is only one of the determinants of our variant ways of understand-

${ }^{199}$ For example:

[I]deology seems to function best when no one believes in it; more than that, belief, and even belief in the ideology's own principles and assumptions, appears as its greatest enemy. Utopia is not the triumph of (rational) belief but, on the contrary, the total interdiction of belief. Wittingly or unwittingly, the great modern philosophies of suspicion and derealization have brought their modest contributions in that direction ...."

Matei Calinescu, From the One to the Many, in ZeITGEIST IN BABEL 156, 172 (Ingeborg Hoesterey ed., 1991).

${ }^{200}$ Hoy, supra note 197 , at 138. Mark Tushnet contrasts the same two approaches when he says,

[a] fanatic adherent of the hermeneutic method might deny that we can ever understand the past because the world of the past is not the world within which we have developed ways of understanding how others act. That, however, goes too far. We can gain an interpretive understanding of the past by working from commonalities . . both immanent in our history and constructed by us as we reflect on what our history is.

TUSHNET, supra note 50, at 44. 
ing experience. We are different not only from our ancestors, but also from each other. And yet our differences must be understood as variations on shared themes: what makes our practices shared is the extent to which we can transcend individual strategies, apprehending and appreciating the alternatives encompassed by the shared practice.

\section{Applying the Lessons: Pragmatism as Legal Theory}

What do we gain by thinking of law as a deliberative practice? Is the notion merely a description of law and legal reasoning? Is it theory? If it is theory, does this label imply that it facilitates substantive work, for example judicial decision-making and the evaluation of judicial decisions?

Implicit in the description of law as a deliberative practice is neither hope nor despair. By "hope" I mean something quite specific: the aspiration to make hard cases easy (or easier) by showing that one approach to decision-making is fundamentally correct. Consensus theory is an expression of this kind of hope. ${ }^{201}$ Hope in this sense, a malady of philosophers, differs from run-of-the-mill hope, the hope that one's resolution of a hard case will convince others. The first kind is the hope of reconceiving an array of approaches by making a foundational theoretical advance; the second is the hope of applying one's own approach in a persuasive way.

By "despair" I mean a solipsistic conviction that conceptual diversity is unbridgeable in principle. Such despair differs from the despair that one's own answers and strategies of argument will prove unpersuasive in particular cases and also from the despairing realization that human deliberation will always be diverse in approach and result. Deliberative practices involve bridgeable diversity.

The philosophical kinds of hope and despair that must be rejected are based on distorted pictures of actual deliberation. Wittgenstein says that philosophy "leaves everything as it is." 202 This comment is notoriously open to many interpretations. ${ }^{203}$

${ }^{201}$ See Thomas C. Grey, Holmes and Legal Pragmatism, 41 STAN. L. REv. 787, 799 (1989) (contrasting the traditional Western philosophical goal of establishing a foundation of knowledge on basic indubitable beliefs with the pragmatist's claim that knowledge is dependent on context).

202 WITTGENSTEIN, supra note 22 , at 49.

${ }^{203}$ See ACKERMAN, supra note 17, at 205 (stating that "Wittgenstein wants to keep 
One plausible interpretation is that theoretical speculation explains our deliberative practices and, in doing so, dissolves misconceptions about practices but does not change them. Speculating about judicial decision-making does not make hard cases easy, but neither does it make them impossible by showing that what appears to be a debate among reasoning strategies is really a confrontation of hermetically-sealed conceptual systems. My description of deliberative practices follows this sense of Wittgenstein's dictum.

The suggestion that law is a deliberative practice is similar in some ways to recent accounts offered by so-called "legal pragmatists." ${ }^{204}$ Certainly the goals of the two accounts seem similar, as Thomas Grey implies in his contribution to a recent symposium on legal pragmatism:

[I]n its very modesty, pragmatism always threatens to usher itself from the philosophical scene. ... The pragmatist says that theory is no more than commentary on practice, based on premises drawn from that practice itself or from other practices. This account of theorizing sounds question-begging to the standard theorist; its self-imposed practical test (theorize to improve practice) invites responsive insistence on some independent (i.e. "genuinely theoretical") criteria by which "improvement" can be identified. $^{205}$

While law as a deliberative practice disappoints the same "theoreti-

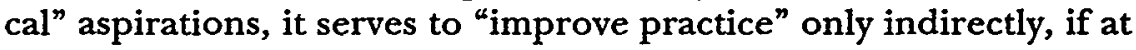
all. It affects practice through self-awareness, through fostering the

the differences, the jagged edges, and accept what is obviously fragmentary, contextual, and incomplete"); S. STEPHEN HILMY, THE LATER WITTGENSTEIN 205-06 (1987) (stating that Wittgenstein regards philosophy as only descriptive); ANTHONY KENNY, THE LEGACY OF WITTGENSTEIN 45 (1984) (stating that "Wittgenstein insists that philosophy is only philosophical problems. The survey which you make does not give you the kind of totally new understanding, a surplus understanding, it merely removes the philosophical problems.").

${ }^{204}$ Posner argues that

[a]lthough pragmatic jurisprudence embraces a richer set of ideas than can be found in The Nature of the Judicial Process or "The Path of Law," one can hardly say that there has been much progress, and perhaps in the nature of pragmatism there cannot be.... [Pragmatism] signals an attitude, an orientation, at times a change in direction. It clears the underbrush; it does not plant the forest.

Richard A. Posner, What Has Pragmatism to Offer Law?, 63 S. CAL. L. REV. 1653, 1670 (1990).

205 Thomas Grey, Hear the Other Side: Wallace Stevens and Pragmatist Legal Theory, 63 S. CAL. L. REv. 1569, 1591 (1990). Grey goes on to say that theories offering such independent criteria "are not to be had." Id. In this conclusion, he agrees with those who view law as a deliberative practice. 
self-consciousness examination of one's assumptions and methods.

How does legal pragmatism compare with the account of law that we have been investigating? Legal pragmatists, as we shall see, arrive at their conclusions by a different route, by appropriating rather than distinguishing the skeptical arguments of critical theory. As the label suggests, they draw links to pragmatic philosophers of almost a century ago. ${ }^{206}$

\section{Rorty's Pragmatism}

If the revival of pragmatism could be attributed to one philosopher, it would be Richard Rorty. Admitting that the term is "vague, ambiguous, and overworked," he insists nevertheless that pragmatism "names the chief glory of our country's intellectual tradition." ${ }^{207}$ For Rorty, pragmatism's greatest importance lies in showing that "there are no constraints on inquiry save conversational ones-no wholesale constraints derived from the nature of the objects, or of the mind, or of language, but only those retail constraints provided by the remarks of our fellow-inquirers." 208 Furthermore, "[t]he pragmatist tells us that it is useless to hope that objects will constrain us to believe the truth about them, if only they are approached with an unclouded mental eye, or a rigorous method, or a perspicuous language." 209 Translated into the language of deliberative practices, this means that consensus theory must fail to make hard cases easy because neither the nature of justice nor human need, nor moral insight, nor linguistic purism can reduce the diversity of interpretive strategies for approaching hard cases or determine which strategies are right and which wrong. That question needs to be dissolved, not answered. No transcendental method, but only our awareness of the range of strategies intelligible within our deliberative practices, can constrain our reasoning.

${ }^{206}$ For recent writings on jurisprudence and neo-pragmatism, see id.; Steven D. Smith, The Pursuit of Pragmatism, 100 YALE L.J. 409 (1990); Peter D. Swan, Critical Legal Theory and the Politics of Pragmatism, 12 DALHousIE L.J. 349 (1989); Symposium, The Renaissance of Pragmatism in American Legal Thought, 63 S. CAL. L. REv. 1569 (1990).

207 Richard RoRTy, Consequences of Pragmatism 160 (1982).

208 Id. at 165.

${ }^{209} I d$. 


\section{a. Rorty on Solidarity and Individuality}

The overriding purpose of Rorty's many essays on pragmatism is to refute foundationalism. He views the search for foundations, for a transcendental method, as the prevailing aim and conception of philosophy. There is, however, a more troubling positive side to his analysis: a description of how we are situated as reasoners and what our deliberative practices are like.

What does Rorty mean when he says that the only "constraints on inquiry" are "provided by the remarks of our fellow-inquirers"? Does one who participates in inquiry have no other constraints? For a participant in a deliberative practice, each new question and each new judgment must be fitted into the web of beliefs that one already holds, in which some beliefs are deeply held as criterial and others held more tentatively. One is constrained, as we have seen, by one's stake in a particular way of judging. In the face of sufficiently recalcitrant experience, including the persuasive arguments and accounts of others, many beliefs may be reordered; one's stake may change. Nonetheless, for each of us the diverging strategies of fellow-inquirers are not options equivalent to our own strategies, but challenges to be met and if possible refuted. Thus, Rorty's depiction of the individual's relation to other participants and to the individual's strategies needs examination.

Elsewhere, Rorty states:

There are two principal ways in which reflective human beings try, by placing their lives in a larger context, to give sense to those lives. The first is by telling the story of their contribution to a community.... The second way is to describe themselves as standing in immediate relation to a nonhuman reality.... [S]tories of the former kind exemplify the desire for solidarity, and ... stories of the latter kind exemplify the desire for objectivity....

The tradition in Western culture which centers around the notion of the search for Truth ... is the clearest example of the attempt to find a sense in one's existence by turning away from solidarity to objectivity. The idea of Truth as something to be pursued for its own sake, not because it will be good for oneself, or for one's real or imaginary community, is the central theme of this tradition. ${ }^{210}$

Rorty identifies this move from solidarity to objectivity as the

${ }^{210}$ RICHARD RORTY, OBJECTIVTTY, RELATIVISM, AND TRUTH 21 (1991). 
mistaken move of philosophy. He sees this philosophical gesture as a kind of blindness, blindness to the limits of deliberative practices. ${ }^{211}$

The problem with Rorty's preference for solidarity over objectivity is that it is relevant solely at the level of theory and not at the level of the participant. The sense of "standing in immediate relation to a nonhuman reality" is itself immediate. How could experience be otherwise? The impulse to apply strategies of understanding to find out how things are in "nonhuman reality"what is behind the tree, what is the sum of these numbers, what is the geography of Antarctica-arises spontaneously as an end in itself. $^{212}$ Our stake is expressed in the strategies we employ to answer these questions and in regarding them as yielding truth, as putting us in touch with how things are. Even if truth is not the guarantor of what these strategies yield, as Rorty is correct in asserting, it is the product of what the strategies yield.

\section{b. Rorty on Theory and Practice}

Taken as descriptive of experience, Rorty's account is paradoxical because it represents participation from the outside rather than the inside. From the standpoint of an outsider/theorist, the practice is indeed, as Rorty says, limited only by the collection of available strategies; ${ }^{213}$ truth and reality are whatever those strategies yield. ${ }^{214}$ But to say this is to lose sight of the point of view of the insider. And ultimately, all of us experience ourselves as insiders for whom objectivity, or rational deployment of strategies for arriving at what we regard as truth, matters.

Rorty, in other words, speaks from an impossible position, that of the pure outsider who is not a participant in practices and

211 See id. at 24.

212 The givenness of experience is a central issue for epistemology. See ARTHUR C. DANTO, ANALYTICAL PHILOSOPHY OF KNOWLEDGE 141-42 (1968) (stating that even "if we are in fact products of our experience, this fact is irrelevant to the externality of experience as an epistemological relationship"); D. HAMLYN, THE THEORY OF KNOWLEDGE (1970).

213 See supra text accompanying note 208.

214 When presented this way, Rorty's argument has most of the earmarks of what Dworkin describes as "external skepticism." Dworkin describes external skepticism as "a metaphysical theory, not an interpretive or moral position. . . . [The] theory is rather a second-level theory about the philosophical standing or classification of [substantive] claims. ... [Such] skepticism is external because disengaged: it claims to leave the actual conduct of interpretation untouched by its conclusions." DWORKIN, supra note 36 , at 79-80. 
Rorty's recommendations about using the notions of truth and objectivity are made from that perspective. The position is an archetypical kind of skepticism that has always had proponents. ${ }^{215}$ Given this perspective, how can one characterize Rorty's own analysis? Is it true and objective as a description of the limits of language? Or is it, on the other hand, simply an expression of solidarity with a linguistic and conceptual community? Rorty aspires to the first characterization and not the second. ${ }^{216}$ From the point of view of insiders to the practice shared with Rorty, these claims aim to state what is true and to do so objectively.

Another difficulty in Rorty's position echoes the main themes of this essay. Why does Rorty refer so often to "communities" and so rarely to individuals? Why is solidarity with a community the concept that supplants or corrects the aspiration to objectivity? The clue again lies in Rorty's adoption of the point of view of the outsider. What is essential to individual (insider) self-awareness is what I have called a stake in a particular way of organizing experience, particular strategies of understanding. Each person's strategies are the unique product of a unique history and unique capacities. Because recalcitrant experience is always possible, one's identification with the shared community in which one has learned these strategies is always in principle subject to rupture.

Individuality in this sense gets short shrift from Rorty. Identifying himself as one of the "partisans of solidarity," 217 he says that "[i]nsofar as a person is seeking solidarity, she does not ask about the relation between the practices of the chosen community and something outside that community." 218 Awareness and selfquestioning about the diverse strategies of a deliberative practice are the essence of individuality and are antithetical to solidarity. ${ }^{219}$

215 See, e.g., STRAWSON, supra note 68, at 106 (stating that one cannot ascribe "states of consciousness to oneself, or at all, unless the ascriber already knows how to ascribe at least some states of consciousness to others .... [W] must accept [this conclusion] in order to explain the existence of the conceptual scheme in terms of which the sceptical problem is stated.").

216 See RORTY, supra note 4 , at 315-94.

217 RORTY, supra note 210 , at 33 .

218 Id. at 21.

219 Rorty is keenly sensitive to the idea that choice is a condition of solidarity and that privacy matters.

[T] he important questions will be about what sort of human being you want to become. ... [T] $]$ his question will divide into two subquestions. The first is: with what communities should you identify, of which should you think of yourself as a member? The second is ... what should I do with my loneness? 
Rorty insufficiently distinguishes two roles of community, and therefore two senses of solidarity. One sense refers to each person's debt to her history. In this sense, "community" identifies the context of learning, of becoming a participant in practices. Solidarity with that community is never entirely chosen and is likely to be ruptured over time as one shapes one's ways of thinking around the recalcitrant experiences of life. The other sense of solidarity is one's chosen identification with those who are likeminded. Shared values, backgrounds, and ways of organizing thought ground such voluntary associations, which are always subject to revision; opting out is always a possibility. Solidarity in this sense is never perfect unless it subverts what is individual and unique. Individuality appears in the transition from community in the first sense to community in the second.

\section{c. Rorty's Influence}

Some critical theorists identify the justificatory and conceptual strategies of individuals with those of discrete communities. Many of them assume, as we have seen, that value "systems" or conceptual "systems" stably define such communities. A failure to address the relation of individual to community allows them to assume that race, class, and gender define separate domains and that individuals simply express and represent the shared experience and understanding of such domains/communities. ${ }^{220}$

Martha Minow and Elizabeth Spelman, for example, assert that for Rorty language "reflects particular human cultures" and describe him as recommending that "it [is] better to speak within particular communities about contingent practices. ${ }^{n 21}$ Joseph Singer draws from Rorty the insight that "[a]ll objectivity means is agreement among people. ... [O]bjective principles are principles . . . people accept." 222 The outsider standpoint that these writers borrow

Id. at 13

${ }^{220}$ See supra text accompanying notes 182-92.

221 Martha Minow \& Elizabeth V. Spelman, In Context, 63 S. CAL. L. REV. 1597, 1611 (1990).

222 Joseph Singer, The Players and the Cards: Nihilism and Legal Theory, 94 YALE L.J. 1, 35 (1984).

Compare this to the view that objectivity means adherence to a principled and consistent way of forming judgments, one that is as free as possible of accidental emotional bias. All of us have, among our strategies of understanding, ways of checking for consistency and bias as well as relevant modes of self-questioning. Application of these checks and balances sometimes compels us to arrive at different 
from Rorty collapses the individual's modes of judgment into those of the group.

More recently Singer has faced the dilemma that this reductive move sets up: the paradox of understanding how the individual, whose resources are reduced to those of the group, can possibly differentiate herself from the group and employ a way of judging that opposes it. Singer accuses Rorty of conservatism, of "deferring to the immanent values of 'our' culture," and urges the "need to understand how our ways of describing the world ... reinforce the power of dominant groups ... [and the need to understand] the ways in which our categories ... reinforce illegitimate power relationships." ${ }^{223}$ Both the view that Singer criticizes in Rorty and the view that he commends assume that one must choose between conceptual schemes attributable to groups, either the schemes of the dominant class or of the dominated class. Thus, Singer identifies the individual's possibilities with the experience of the group. He also assumes that reasons for judgment are homogeneously classifiable as reasons that reinforce power or that undermine it.

Rorty is therefore seen as discussing value systems or conceptual schemes that are group or class-based. Arguing against an objectively privileged method of understanding, he disparages truth and objectivity by assuming the standpoint of an outsider to any particular practice. He invites the conclusions that the insider's aspiration for truth and objectivity is an illusion and that the individual simply represents the group: discourse is simply a "conversation" among exemplars of discrete conceptually-separated groups. Group-based conceptual schemes subvert the distinctiveness of the individual's unique strategies of understanding and the perspective that the individual as insider deploys toward truth.

By contrast, attention to deliberative practices stresses that each individual's strategies are unique and that shared recognition of strategies is essential to the existence of a practice. It also shows that theorists who talk about truth and objectivity must attend to the ways in which participants in practices understand truth and objectivity. Rorty's remarks on truth and objectivity reflect an attempt to transcend particular strategies. But we remain participants, unable to ascend with Rorty to the ethereal realms and to

judgments and use different principles than those with whom we deliberate. 1769 .

223 Joseph Singer, Should Lawyers Care About Philosophy?, 1989 DUKE L.J. 1752, 
absorb the chaste linguistic admonitions of pure theory. ${ }^{224}$

\section{Fish and Interpretive Communities}

The critic Stanley Fish is, if anything, even more acute and persuasive than Rorty in showing the mistakes of foundationalism in the context of describing deliberative activities. Challenging the suggestion of consensus theory that “disciplining rules' ... will constrain readers or interpreters and mitigate (if not neutralize) the inherent ambiguity of texts," and that the rules will "tell you what to do and prevent you from simply doing whatever you like," Fish argues that rules cannot have this kind of independence as constraints because they do not "declare their own significance to any observer, no matter what his perspective. ${ }^{n 25}$ For each interpreter the rules have an idiosyncratic place within her own interpretive strategies. Given the stake each person has in such strategies, "one cannot," according to Fish, "be meaningfully urged to become more flexible or generous in one's thinking .... [A]lthough flexibility and openness may well be the pattern human cognitive performance traces out, it cannot be a program a human performer might self-consciously enact. ${ }^{226}$ Clarifying this, Fish explains that he is not saying "that beliefs (and therefore consciousness) cannot change, only that change will not be from a state of undoubted belief to a state in which the grip of belief has been relaxed, but from one state of not-at-the-moment-seen-around belief to another. ${ }^{n 227}$

\section{a. Fish and Deliberative Practices}

These descriptions resonate particularly well with the idea of being situated in a deliberative practice. For example, Fish persuasively criticizes Catharine Mackinnon in saying that she "is not, despite her own pronouncements, exhorting us to a new way of knowing, but to know different things than we currently know

${ }^{224}$ It may seem ironic to criticize Rorty on these grounds, since he himself insists that all discourse is part of a conversation among participants in a practice and that pure theory is an illusion. However, my argument is that he is inconsistent in holding that ordinary language is the only language we have, while at the same time taking a skeptical and revisionary stance toward the concepts of truth and objectivity. He denies that his position is skeptical or revisionary. See generally RORTY, supra note 4.

${ }^{225}$ Fish, NATURALLY, supra note 19 , at 121 .

$226 I d$. at 16.

227 Id. at 18. 
(about rape, pornography, etc.) in the same (and only) way we know anything, by having been convinced of it." ${ }^{228}$ In this view, it is sensible to interpret feminist theorists not as urging us to reject and replace conceptual schemes but as commending new ways of putting together familiar and unfamiliar experiences by using mutually intelligible strategies of understanding.

Similarly, Fish contends that, although he is not concerned with "deny[ing] the distinction between continuing and inventing, . . . as in the case of explaining versus changing, the distinction is interpretive and . . . because it is interpretive, one cannot determine whether a particular piece of behavior is one or the other by checking it against the text." ${ }^{229}$ In other words, from the standpoint of her own interpretive strategies, each judge will see herself as continuing a course of judgment faithful to existing law and will see others as inventing new law. "[I]nsofar as the distinction is a mechanism for distinguishing between two forms of judicial activity ... it won't work because there is no independent way of determining whether or not a particular judge is acting in one way [or] the other. ${ }^{n 30}$ Fish seems to say that such distinctions make sense for the insider but not the outsider.

\section{b. Fish as Pure Theorist}

Often, however, Fish himself takes the standpoint of outsider and seems to declare the distinctions meaningless altogether. "The distinction between a 'found' history and an 'invented' one is finally nothing more than a distinction between a persuasive interpretation and one that has failed to convince." 231 This echoes Rorty's pragmatic claim that successful persuasion is the only measure of truth.

But for the insider, predictions of persuasive success cannot be a criterion for truth. For a participant in a deliberative practice, for instance the judge deciding a case, there is all the difference between the argument that flows from his commitments, his strategies of understanding, and an alternative argument he can imagine constructing, or inventing. The distinction has little if anything to do with its anticipated persuasive power.

${ }^{228} I d$. at 21.

229 Id. at 109.

${ }^{230} \mathrm{Id}$. at $109-10$.

231 Stanley Fish, Working on the Chain Gang: Interpretation in Law and Literature, 60 TEX. L. REv. 551, 559 (1982). 
Fish also speaks as an outsider when he says that "[i]n searching for a way to protect against arbitrary readings (judicial and literary), Dworkin is searching for something he already has and could not be without. He conducts his search by projecting as dangers and fears possibilities that could never be realized." 232 What does Fish mean by saying that arbitrary readings are not possible? Insider/ participants have criteria for what they call arbitrary readings. They reject some readings (and some justificatory arguments) as arbitrary when they are poorly grounded even in the proponent's own reasoning strategies. On the other hand, for the theorist as outsider, there is indeed no transcendental criterion for arbitrariness when she, as theorist, compares one justificatory strategy with another. But to say that all readings are equally arbitrary (or nonarbitrary) is doubly misleading, both because there can be no standard for determining equal (or unequal) arbitrariness and because each of us is in fact an insider, disposed to reason in a particular way and to deploy internal criteria of arbitrariness. None of us is in a position to occupy the pure outsider's seat. ${ }^{233}$

\section{c. Fish on Interpretive Communities}

In using Fish's writings, theorists tend to assimilate the perspective of the individual into the conceptual categories of the group. ${ }^{234}$ Fish's own statement of the notion of an interpretive community, one of his main themes, is ambiguous. He says that

[i]nterpretive communities are made up of those who share interpretive strategies not for reading but for writing texts .... [S]ince the thoughts an individual can think and the mental operations he can perform have their source in some or other interpretive community, he is as much a product of that community (acting as an extension of it) as the meanings it enables him to produce. ${ }^{235}$

232 Id. at 562.

${ }^{233}$ Therefore, I regard Fish's comments on the concept of arbitrariness as revisionary from a skeptical standpoint, just as Rorty's comments about truth and objectivity turn out to be revisionary. Both, in spite of themselves, commit the skeptical maneuver analyzed and criticized by Strawson. See STRAwSON, supra note 68, at 103-10.

234 Douzinas's recent critical study of postmodern jurisprudence claims that for Fish "every community of interpreters, lawyers and judges, for example, develops its unique sense of professional competence, etiquette and good sense, with its own tacit and explicit conventions." Douzinas, supra note 6, at 138.

235 FISH, TEXT, supra note 19, at 14. David Luban's discussion of ambiguity in Fish's account of interpretive communities and institutions raises the issue of whether 
The terms "share," "source," and "product" are all ambiguous. Do persons share strategies only when their strategies are the same or whenever they have overlapping and mutually intelligible strategies? Does Fish mean in referring to sources and products that individuals are limited by and reducible to the strategies they share with all members of the community, or is he saying merely that the origins of interpretive strategies are in the community and that its resources are their endowment and history? The latter reading sheds light on the situation of the individual in a deliberative practice. The former reading ignores individuality and lends itself to caricature, the picture of discrete and isolatable conceptual systems which is at the heart of some critical writings.

\section{Acceptable Pragmatism and Banal Pragmatism}

Legal (neo-)pragmatism has an individualist face which takes account of the differences of individuals within practices and a collectivist face which ignores such diversity. Theorists such as Rorty and Fish slip from the individualist to the collectivist position. The collectivist position rests on the idea of a homogeneous interpretive community, on unreflective solidarity with like-minded persons.

The elements of the collectivist position are simplifications of reality, traps for critical theorists. Accordingly, on the collectivist view, the individual is merely a manifestation of the community, identifiable by its shared value system or shared conceptual framework. Disagreement is nothing more or less than a conversation among members of different interpretive communities. Truth is nothing more than a label for the interpretive strategy that happens to persuade and prevail in the conversation.

These collectivist theses are congenial to writers who assume that the powerful and the powerless, the genders, and the several races define discrete conceptual systems at war with one another, and that nothing more can be said for judgments than that they reflect one system or another. I have considered at length what is wrong with the collectivist picture: it disregards the idiosyncratic strategies of individuals, the stake each has in her strategies, the implications of that stake for the use of terms like "truth" and

Fish extends his strictures to institutions/communities in which "members disagree over interpretive strategies." See David Luban, Fish v. Fish or, Some Realism About Idealism, 7 CARDOZO L. REV. 693, 694 (1986). 
"objectivity," and the way in which the use of these terms illuminates the tension between having a stake and being aware that one's practices are not grounded in transcendental foundations (criteria outside the practice itself). All of these dimensions of deliberative practices are part of the individualist story, lost in the collectivist story.

The individualist story is reflected in some recent writings by jurisprudential neo-pragmatists. Thomas Grey describes "the pragmatists' first thesis [as the view] that knowledge is essentially contextual, situated in habit and practice. . ."236 This thesis implies "a kind of perspectivism. Because new beliefs emerge out of a complex of already existing beliefs that can never be made fully conscious and explicit, all useful beliefs may not ultimately prove commensurable with each other."237 Applied to law, pragmatism claims that law "is constituted of practices-contextual, situated, rooted in custom and shared expectations," and that law is "instrumental, a means for achieving socially desired ends. ${ }^{\text {238 }}$

For individuals bound in a shared deliberative practice, the deployment of shared and individual strategies of interpretation serves ends which are themselves the subject of debate and disagreement. Accordingly, Grey comments that "pragmatism mediates between positivistic and instrumentalist conceptions of law on the one hand and, on the other, idealist legal theories that identify law with the aspiration to justice, and see legal ideas as partly constitutive of social reality."239 Pragmatism, therefore, reflects the individual decision-maker's commitment to a particular stake in justice as well as her awareness of deliberation as an instrumental practice serving controversial ends.

Grey also takes note of "pragmatism's peculiar rhetorical disadvantages vis-á-vis other theories. ... For pragmatists, any theory is only a set of reflections on some existing practice, generated out of and attached to that practice, recognizing its contingency and cultural particularity." 240 Rorty similarly dwells

236 Grey, supra note 201, at 799. The idea of knowledge and judgments as relativistic, contingent, and historically based existed long before the arrival of contemporary pragmatism; indeed, this concept played a central role in some major strains of nineteenth-century and earlier social thought. See id. at 801-03.

${ }^{237}$ Id. at 804.

238 Id. at 805 .

239 Thomas C. Grey, The Wallace Stevens Case: LAW and the Practice of POETRY 68-69 (1991).

210 Id. at 105. 
on "the banality of pragmatism" as a theory that largely "clears the underbrush and leaves it to others to plant the forest."241 The underbrush in this case is the foundational background of legal formalism, representing the aspiration to make hard cases easy by finding uncontroversial and acontextual modes of decision. ${ }^{242}$

Some limits of pragmatism, seen as contextualism and instrumentalism, are brought out by Margaret Jane Radin when she asks, "How can the pragmatist find a standpoint from which to argue that a system is coherent but bad, if pragmatism defines truth and good as coherence? Inattention to this problem is what makes pragmatism seem complacent, when it does." 243 Viewing the individual's strategies as contextual and seeing the community as a context with instrumental criteria for truth can be criticized as vague and banal. It does not explain how the individual distinguishes himself from the group, how disagreement within the group is possible, and how it is resolved. Even when pragmatism does not take its collectivist posture and identify the individual with the group, it still does not give an account of the relationship between the two. It does not wade deeply enough into the structure of deliberative practices.

\section{CONCLUSION}

Legal philosophers have generally spotlighted one act in the complex drama of law and one question in a seamless web of issues. The act is deliberation and decision-making by judges and the question is how the nature of law manifests itself in judicial deliberation. This preoccupation is shared by legal theorists who share little else.

The metaphors and assumptions of legal theorists have characteristically oversimplified judicial agreement and disagreement. Some theorists see judges as joint players of a game with identifiable rules, rules that define which moves are allowed and what resources

${ }^{241}$ Richard Rorty, The Banality of Pragmatism and The Poetry of Justice, 63 S. CAL. L. REV. 1811, 1813, 1815 (1990) (discussing Posner's characterization of pragmatic jurisprudence).

242 In that respect, pragmatism repeats the well-digested lessons of legal realism, translated into lessons about language and understanding. $C f$. id. at 1813 (stating that "new pragmatists talk about language instead of experience or mind or consciousness ....".

243 Margaret Radin, The Pragmatist and the Feminist, 63 S. CAL. L. REV. 1699, 1710 (1990). See also Frank Michelman, Private/Personal but Not Split: Radin Versus Rorty, 63 S. CAL. L. REV. 1783 (1990) (comparing Rorty's pragmatic view of a public-private split with Radin's rejection of such a dichotomy). 
can be used. But the game metaphor cannibalizes itself, in part because the rules themselves are the subject of decision-making. An even more misleading variant of the shared-rules model describes judges as joint elaborators of a shared consensus about goals and values.

On the other hand, it is equally misleading to ignore the ties that bind judges into a shared practice. Some theorists, drawn to a subtext of conflict for the sake of domination and of irreconcilable conceptual schemes, flirt with solipsism of the individual or of the group. They ignore that the individual judge is more than a locus of idiosyncratic value or idiosyncratic techniques of understanding, representative only of himself or his group. He is also a participant in a shared practice with other judges, a deliberative practice in which arguments are mutually understood and anticipated and in which mutual influence can and does occur.

Seeing legal reasoning as a deliberative practice focuses attention on two aspects of judging and its implications for law. The first aspect is the complexity of each individual judge's ways of understanding, of making and justifying decisions, and of determining what is and is not legally relevant to a particular case. The arguments that she uses with justificatory force will be configured in a way that reflects her unique way of understanding experience, her knowledge-and her way of understanding the point of law and laws. Her uniqueness is not simply a matter of ethics and politics but a way of situating ethics and politics in a general scheme of understanding.

The second aspect is that, if she is reflective, she will appreciate that other judges have their own ways of understanding experience and accordingly make different kinds of justificatory moves. Her recognition of this, and her familiarity with the conceptual styles of others, constitute her awareness of the joint deliberative practice. This awareness is characterized by the tension between the unavoidable and all-pervasive stake she has in her modes of understanding and her understanding that she is just one of many equally situated participants, that her ways of proceeding have no special sanction. To divorce this last insight from the simultaneous awareness of her stake and to imagine a position outside any particular way of understanding is to divorce theory from practice.

Thinking of law as a deliberative practice allows us to reconceive the fluidity and the boundedness of law. The concept of law refers to several things. First, the law for each judge, and for each observer, consists of decisions and justificatory arguments that that 
judge regards as appropriate given her ways of reasoning and her sense of law's purposes. Second, the law may include the collection of decisions and justificatory strategies that are mutually regarded as legally relevant. Finally, the law may be said to refer to decisions apart from the justificatory arguments supporting them.

This third account of law requires it to be possible to identify decisions, identify the law, apart from underlying justificatory arguments. I have argued that this is not possible. The first and second account, however, are alternative ways of saying that law is as fixed and as fluid as the justificatory strategies that are mutually recognized as relevant.

If Wittgenstein is right, and if philosophy "leaves everything as it is," then describing law as a deliberative practice can be neither conservative nor radical. The law itself, the deliberative practice that is law, will be conservative if the society is homogeneous or successfully repressive, if new voices and ways of thinking remain unrepresented. The law will be radical if society is heterogeneous and new ways of justifying and conceiving aims are continually given legal expression. The law will, furthermore, be liberal in Mill's sense whenever it is open to new ways of thinking, whenever judges recognize that their ways of reasoning and justifying, i.e. their stake, do not necessarily have hegemony. 